\title{
An immersive virtual reality game to train spatial attention orientation after stroke: a feasibility study
}

Hanne Huygelier ${ }^{1}$, Brenda Schraepen ${ }^{1}$, Christophe Lafosse ${ }^{2}$, Nathalie Vaes ${ }^{2}$, Fabienne Schillebeeckx ${ }^{3}$, Karla Michiels ${ }^{3}$, Eline Note ${ }^{3}$, Vero Vanden Abeele ${ }^{4}$, Raymond van Ee ${ }^{1,5}$, Céline R. Gillebert ${ }^{1}{ }^{*}$

\author{
${ }^{1}$ Brain and Cognition, KU Leuven, Leuven, Belgium \\ ${ }^{2}$ Scientific Unit Rehabilitation Hospital RevArte, Antwerp, Belgium \\ ${ }^{3}$ Rehabilitation centre Pellenberg, University Hospital Leuven, Leuven, Belgium \\ ${ }^{4} \mathrm{HCl} / \mathrm{eMedia}$, Department of Computer Science, KU Leuven, Leuven, Belgium \\ ${ }^{5}$ Donders Institute for Brain, Cognition and Behavior, Radboud University, Nijmegen, The \\ Netherlands
}

*Corresponding author: celine.gillebert@kuleuven.be, Department of Brain and Cognition, Tiensestraat 102 box 3711, 3000 Leuven, Belgium, +32 16372704

This is an Accepted Manuscript of an article published by Taylor \& Francis in Applied Neuropsychology: Adult on the $5^{\text {th }}$ of September 2020, available online:

http://www.tandfonline.com/10.1080/23279095.2020.1821030." 


\begin{abstract}
Immersive virtual reality (IVR) may boost neglect recovery, as it can provide an engaging experience in a 3D environment. We designed an IVR rehabilitation game for neglect patients using the Oculus Rift. Multisensory cues were presented in the neglected visual field in a patient-tailored way. We acquired pilot data in 15 neurologically healthy controls and 7 stroke patients. First, we compared cybersickness before and after VR exposure. Second, we assessed the user experience through a questionnaire. Third, we tested whether neglect symptoms corresponded between the VR game and a computerized cancellation task. Fourth, we evaluated the effect of the multisensory cueing on target discrimination. Last, we tested two algorithms to tailor the game to the characteristics of the neglected visual field. Cybersickness significantly reduced after VR exposure in six stroke patients and was low in healthy controls. Patients rated the user experience neutral to positive. In addition, neglect symptoms were consistent between a computerized cancellation and VR rehabilitation task. The multisensory cue positively affected target discrimination in the game and we successfully presented sensory stimulation to the neglected visual field in a patient-tailored way. Our results show that it is promising to use gamified patient-tailored immersive VR for neglect rehabilitation.
\end{abstract}

Keywords: hemispatial neglect, virtual reality, rehabilitation, stroke, feasibility, HEMIRehApp 


\section{INTRODUCTION}

Hemispatial neglect is a complex neuropsychological syndrome frequently occurring after unilateral stroke. Neglect patients typically fail to detect or respond to stimuli on their contralesional side (Heilman et al., 1987). Although the prevalence estimates of neglect vary across studies (Bowen et al., 1999), hemispatial neglect has consistently been associated with worse post-stroke recovery of postural control and upper limb motor functioning (Nijboer et al., 2014; van Nes, van der Linden, et al., 2009; van Nes, van Kessel, et al., 2009), and worse daily life functioning (Nijboer et al., 2013).

There is a paucity of effective rehabilitation techniques for hemispatial neglect. A systematic review in 2013 concluded that there is no effective cognitive rehabilitation for hemispatial neglect (Bowen et al., 2013). Cognitive rehabilitation encompasses strategies that either teach patients how to compensate for their neglect (e.g., visual scanning training) or strategies that aim to alter the underlying spatial impairments through various bottom-up stimulation techniques (e.g., passive or active limb activation, prism adaptation, optokinetic stimulation, galvanic vestibular stimulation) (Bowen et al., 2013). Researchers have also explored other techniques such as non-invasive brain stimulation (Salazar et al., 2018) and pharmacological treatments (van der Kemp et al., 2017). A recent meta-analysis concluded that there was moderate-quality evidence in favour of the effectiveness of non-invasive brain stimulation (Salazar et al., 2018). In contrast, there was little evidence for the effectiveness of pharmacological interventions (van der Kemp et al., 2017).

In recent years, cognitive treatment using virtual reality (VR) has also been suggested as a potential avenue toward effective rehabilitation of hemispatial neglect (Fasotti \& van Kessel, 2013; Pedroli et al., 2015; Tsirlin et al., 2009). However, none of these newer methods have reached clinical practice yet (Chen et al., 2018). Interestingly, a recent survey showed that clinicians viewed non-invasive brain stimulation and pharmacological treatments as less feasible or desirable to use in clinical practice than VR (Chen et al., 2018). Therefore, it is important to explore the potential of VR for rehabilitation of hemispatial neglect.

\subsection{VIRTUAL REALITY REHABILITATION OF HEMISPATIAL NEGLECT}

VR offers many opportunities for rehabilitation (Fasotti \& van Kessel, 2013; Pedroli et al., 2015; Tsirlin et al., 2009). It allows for presenting complex, dynamic, interactive and realistic 3D scenarios to patients. This may increase the ecological validity of training tasks and could produce better transfer of training into daily life (Rizzo et al., 2004). Furthermore, unlike the real world, VR allows more control over the stimulus environment, which can aid standardization of behavioural measurements (Foerster et al., 2016). An additional advantage of VR rehabilitation is that it allows to measure behaviour in a detailed way which can be used to give automated feedback on patient's behaviour (Rizzo et al., 2004). 
Immersive VR Neglect Rehabilitation Some researchers have developed VR tools for neglect rehabilitation (Table 1). The term VR has been used to refer to semi-immersive VR systems using a regular 2D monitor with a limited field of view or a large projection, but also to more immersive systems (Table 1). We identified six systems that used a headmounted display (HMD) of which three studies used an HMD with lower quality than current HMDs such as the Oculus Rift or HTC Vive, two studies used the Oculus Rift development kit and one study used the FOVE HMD, which is a headset that includes an eye-tracker (Table 1). There was also considerable variability in the input devices used to interact with the systems (Table 1). Six systems used a motioncapture camera that tracked patient's upper-limbs or body. Two systems used haptic force-feedback devices that can simulate a touch sensation, one system tracked hand movements with a data glove, one system used a steering wheel and one system used a computer mouse. Thus, few studies have explored the potential of the newest generation of commercially available immersive VR headsets, such as the Oculus Rift CV1 or the HTC Vive.

The therapeutic principles underlying the VR systems also varied. There were two systems that developed a VR alternative to prism adaptation (Ansuini et al., 2006; Castiello et al., 2004; Won-Seok et al., 2017), in which a dissociation was introduced between the real and virtual position of the hand (Table 1). Researchers have also used VR to block parts of the ipsilesional visual field in order to promote contralesional orientation (Myers \& Bierig, 2000; Yasuda et al., 2017, 2018), resembling the classic approach of eye-patching (Walker, 1996). Many systems used tasks in which patients had to reach or grasp objects on the ipsi- and contralesional side of space, either seeing themselves projected onto the virtual scene (Mainetti et al., 2013; Sedda et al., 2013) or viewing the virtual scene from a first-person perspective (Ekman et al., 2018; Fordell et al., 2016; Luca et al., 2019; Moon et al., 2019; Pirovano et al., 2016; Tobler-Ammann et al., 2017; Yasuda et al., 2017, 2018). In some of the tasks, support was provided to help patients respond to unattended targets, either using sensory cues (Kim et al., 2007; Mainetti et al., 2013; Sedda et al., 2013) or by guiding the contralesional hand towards the target (Ekman et al., 2018; Fordell et al., 2016; Pirovano et al., 2016; Tobler-Ammann et al., 2017).

The extent to which the rehabilitation tasks resembled activities of daily living varied considerably. Two studies used virtual street crossing tasks (Katz et al., 2005; Kim et al., 2007), one used a simple drive simulator (van Kessel et al., 2013) and another used virtual scenarios based on items of the Catherina Bergego Scale (Moon et al., 2019). Additionally, the extent to which gamification was used varied considerably. In one of the rehabilitation games patients lost points when they made errors (Fordell et al., 2016; Pirovano et al., 2016), while in two other games patients received points if they made correct responses (Mainetti et al., 2013; Moon et al., 2019). Moreover, many rehabilitation games used simple stimuli and environments (e.g., cubes and spheres) rather than rich stimulus environments, used a limited game narrative and did not tailor the difficulty of the rehabilitation tasks to individual patients in an automatic way (Table 1). 
Immersive VR Neglect Rehabilitation

\subsection{THE EFFICACY AND FEASIBILITY OF VR REHABILITATION FOR HEMISPATIAL NEGLECT}

The efficacy of these new therapy approaches has been explored in a few studies (Supplementary Table S1). Two studies report data from their rehabilitation tasks with participants using the system for a single session (Aravind \& Lamontagne, 2014; Kim et al., 2007). Other studies used a design without a control group in which patients with stable neglect symptoms participated in multiple sessions of VR therapy. Although these studies often reported improvements after VR therapy, most studies reported inconsistent findings across all the outcome measures or did not statistically test the effects (Fordell et al., 2016; Luca et al., 2019; Mainetti et al., 2013; Yasuda et al., 2018). Moreover, the majority of these studies used classic pen-and-paper assessment tools to evaluate neglect recovery. However, these tools are not ideal to test treatment effects as they lack measurement precision (Bailey et al., 2004; Huygelier et al., 2020).

Moreover, there is a lack of studies that compare different treatment approaches. Only two studies compared the difference in rehabilitation effects between an experimental and control group of stroke patients who completed a different type of therapy for multiple sessions (Katz et al., 2005; van Kessel et al., 2013). In the study of van Kessel et al. (2013), patients in the control group completed standard visual scanning therapy and a simple task in a virtual drive simulator. The experimental group completed the same training, but instead used a dual-task version of the drive simulator task. The experimental group did not show greater improvements than the control group. Katz et al. (2005) compared a semi-immersive VR street crossing training to a semi-immersive visual scanning task and found no evidence for better treatment effects with the street crossing training. Given the lack of studies that have compared an immersive VR training to a placebo version of an immersive VR training, it remains unclear to what extent immersive VR can contribute to rehabilitation of hemispatial neglect. Additionally, there has been little research on the feasibility of these rehabilitation approaches, as only one study investigated how patients and clinicians experienced the VR rehabilitation game and system (Tobler-Ammann et al., 2017).

In summary, more research is necessary to establish the efficacy and feasibility of immersive VR rehabilitation games for hemispatial neglect. For this reason, we designed an immersive VR game for neglect rehabilitation. 
(Myers \& Bierig, HMD (Forte VHX1) Not reported

2000)

(Katz et al., 2005) Computer monitor Not reported

(Ansuini et al., Screen at $50 \mathrm{~cm}$ Data glove and magnetic 2006; Castiello et distance placed on sensor placed on the wrist al., 2004) top of a hollow box (Flock of Birds, Ascension Technology)

(Kim et al., 2007) HMD (unspecified) Computer mouse

(Mainetti et al., A projection screen Sony PS3 EyeToy camera 2013; Sedda et at $1.5 \mathrm{~m}$ distance al., 2013)

(van Kessel et al.,

$2.13 \times 3.18 \quad \mathrm{~m} \quad$ Steering wheel projection screen at distance of $90 \mathrm{~cm}$

(Aravind

\& nVisor SX60 HMD

Lamontagne,

2014)
Virtual home with three rooms. Right side of the visual field is patched. If patient rotated head towards the left side, the patch was removed. Layout of rooms was biased to the left. Virtual objects moved from right to left.

Virtual street crossing. Patients needed to decide when it was safe to cross the street. Difficulty was manipulated by changing the velocity of the car and the side from where cars were approaching the patient.

Patients needed to grasp a real object (a white ball) while seeing a virtual object (replica of real object), while not being able to see their hands. Objects were located either at the centre, or $30^{\circ}$ to the left or right of the centre. In congruent trials, the real and virtual object were located at the same place. In incongruent trials, the real and virtual objects were at different locations. In some of these trials the real object was in the centre or on the right side, while the virtual object appeared on the left.

Virtual street crossing. Virtual car appeared on left or right side. Patients had to indicate when they saw the car. If the patient did not notice the car on time, a visual cue (headlights) was presented. If the car was not noticed after the visual cue, an auditory cue was presented (alarm sound). Difficulty was manipulated by changing the velocity of the car.

Patients saw themselves projected on the virtual scenes. Patients had to grasp objects in the virtual scenes. In stage 1, visual (i.e. blinking) and auditory cues (i.e. spatialized sound) were used to help patients detect the objects. In stage 2 only the visual cues were presented and in stage 3 no cues were presented. In addition, difficulty was manipulated by progressively increasing the number of distractors and targets. If patients made errors, scores were not reduced. When patients gave a correct response, a green checkmark symbol was presented, and the patient received points. Sometimes another rewarding object was presented. Patients played this in multiple scenes they selected themselves.

In the lane tracking task patients had to drive straight on a road. The effect of wind blowing drivers offtrack was simulated and patients had to resist the impact. In the single detection task patients were in the driving scene, but only had to detect visual targets in the centre and left and right to the centre. In the dual task driving simulator patients had to stay on track and detect the targets.

12-camera Vicon-512 Patients viewed a virtual room. In this virtual room there was a blue sphere placed at the end of the motion capture system room and patient's task was to move towards the blue sphere. There were also two red cylinders placed and markers placed on the $30^{\circ}$ to the left and right side. These cylinders moved towards the patient while they were navigating the body to track walking, virtual room and patients' had to avoid colliding with these objects. In one condition, patients had to joystick walk which was captured with a camera. In a second condition, patients navigated the scene using a joystick and had to press a button if they saw the object they were going to collide with. 
(Ekman et al., 2018; 27" monitor viewed Haptic

force

(Phantom Omni)

(Pirovano et al., 2016; 21" monitor at Haptic force

Tobler-Ammann et distance $60-65 \mathrm{~cm}$ with feedback device

al., 2017) chin rest (Falcon Novint)
Fordell et al., 2016) with 3D glasses

\section{t and task}

Patients had to complete a mental rotation task in which 3D figures needed to be moved and placed on the correct location, a visuomotor exploration task in which 3D cubes needed to be placed in straight lines, a visuospatial scanning task in which shapes appeared from above or the left side and shapes needed to be arranged in a puzzle. Visual, sound and vibrotactile feedback were provided. A guiding force pushed the contralesional hand towards unattended targets.

In Balloon Popper, the patient viewed a virtual forest. Red balloons moved around. Patients interacted with the balloons with a hand icon. Blue balloons were added that must not be hit to avoid losing points. In Bubbles Burster, the patient viewed a cauldron with water and bubbles. The patient had to smash bubbles with a stick whose position was controlled by the patient's hand. The patient only needed to smash bubbles of a given color. If the patient smashed wrong bubbles, they lost points. In the puzzle game, the patient saw a puzzle board in the centre and puzzle pieces were spread around it. Through a hand icon, the patient picked up the pieces and placed them inside the board. In the Mix the Soup game, the ingredients were displayed on the left side of the screen whereas the recipe was displayed on the right side. The patient had to remember the initial list and already added ingredients. If the patient added an ingredient which was not on the recipe, they lost points. A guiding force pushed the contralesional hand towards unattended targets.

\begin{tabular}{|c|c|c|c|c|}
\hline $\begin{array}{l}\text { (Won-Seok Kim et al., } \\
\text { 2017) }\end{array}$ & $\begin{array}{l}\text { Oculus Rift } \\
\text { Development Kit } 2\end{array}$ & $\begin{array}{l}\text { Leap } \\
\text { tracker }\end{array}$ & Motion & $\begin{array}{l}\text { Virtual prism adaptation therapy. Patients viewed a virtual abstract representation of a hand that was } \\
\text { either congruent with the real hand location or deviated with a certain angle. Patients had to point } \\
\text { towards the virtual object every three seconds. }\end{array}$ \\
\hline $\begin{array}{l}\text { (Yasuda et al., 2017, } \\
\text { 2018) }\end{array}$ & $\begin{array}{l}\text { Oculus Rift } \\
\text { Development Kit } 2\end{array}$ & $\begin{array}{l}\text { Leap } \\
\text { tracker }\end{array}$ & Motion & $\begin{array}{l}\text { In far space training, patients viewed a virtual screen at } 15 \mathrm{~m} \text { distance. Seven targets that flashed } \\
\text { consecutively were displayed and patients had to orally identify all of them. In near space training, three } \\
\text { target objects were placed on a virtual table in front of the patient and the patient had to reach to each } \\
\text { of these objects. To promote attentional disengagement parts of the visual field were blocked by a } \\
\text { moving slit. }\end{array}$ \\
\hline (Luca et al., 2019) & $\begin{array}{l}\text { A projector or big } \\
\text { screen }\end{array}$ & $\begin{array}{l}\text { Infrared } \\
\text { camera } \\
\text { patient's } \\
\text { movement }\end{array}$ & $\begin{array}{r}\text { video } \\
\text { analysing }\end{array}$ & $\begin{array}{l}\text { In the VR scenarios, audio-visual stimuli were presented in the left, right or in both sides of the virtual } \\
\text { scenario. There were two versions: one with shadow of patient on screen, one without shadow. }\end{array}$ \\
\hline (Moon et al., 2019) & $\begin{array}{l}\text { FOVE Eye Tracking } \\
\text { HMD (viewing angle } \\
100^{\circ} \text { ) with eye tracking }\end{array}$ & Not report & & $\begin{array}{l}\text { In one VR scene, patients viewed a virtual table with food placed on top of it on the left side, center and } \\
\text { on the right side. Patients had to find a certain type of food on the table. As the levels increased, the } \\
\text { target was located more often on the left side. Patients had to search sufficient targets in a level to } \\
\text { reach } 100 \text { points and then moved on to the next level. Audiovisual feedback was given when the patient } \\
\text { finished a level. }\end{array}$ \\
\hline
\end{tabular}




\subsection{INTERVENTION PRINCIPLES}

The proposed rehabilitation game combines seven intervention principles that may positively impact neglect recovery and of which their potential for neglect rehabilitation has not been fully explored yet (Figure 1). We explain each of these intervention principles in detail below.

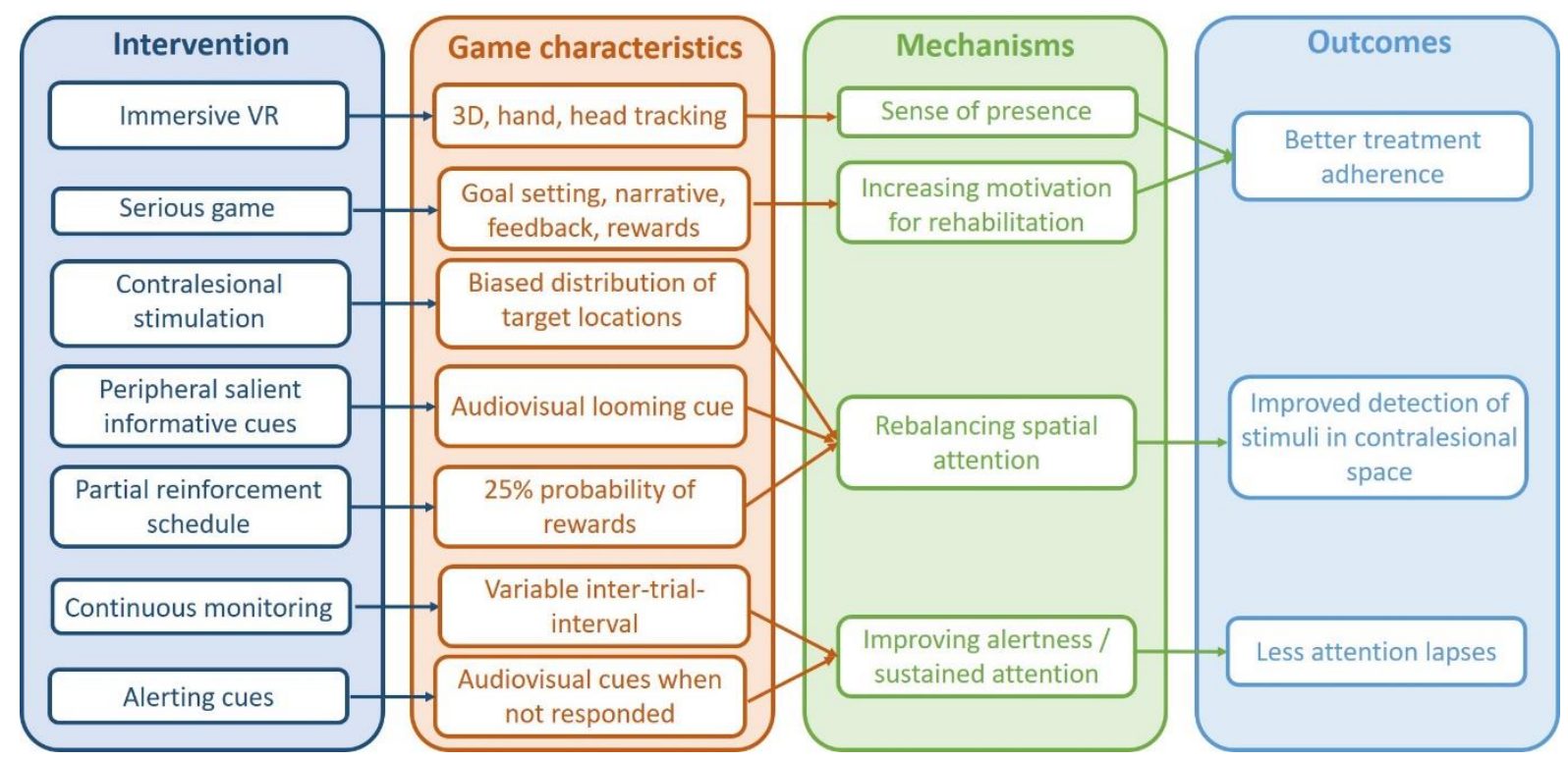

Figure 1. Intervention principles. The seven intervention principles were operationalized into several game characteristics, which are assumed to affect four underlying mechanisms, which should then translate into three observable behavioural outcomes.

\subsubsection{Immersive virtual reality}

A first intervention principle is to use immersive VR using an HMD that tracks patient's head and hand movements and provides a 3D environment surrounding the viewer (i.e., HMD-VR). The immersive nature of the newest generation of HMDs could increase engagement with training tasks, possibly producing better treatment effects (Rizzo \& Koenig, 2017; Tieri et al., 2018). Interestingly, HMD-VR offers the opportunity to systematically register and correct for head movements. In the majority of rehabilitation tasks for neglect patients, patients are free to move their eyes, head and trunk. As neglect patients have a tendency to orient their head and eyes towards the ipsilesional side of space (Fruhmann-Berger \& Karnath, 2005), it is typically difficult to know the true location of the stimulus in the patient's visual field. In one study, researchers aimed to control head movements during rehabilitation using a chin rest, but patients found it unpleasant to have their head position fixed and clinicians did not support this approach as it resulted in bad body posture (Tobler-Ammann et al., 2017). HMDs offer a unique opportunity in this regard, as the head-tracking allows to position the stimuli relative to the head midline thereby overcoming the difficulties associated with head fixation (Figure 2). Moreover, the head position can be a good proxy for the position of the eyes, as human observers typically show coordinated eye and head movements in free viewing (Einhäuser et al., 2009; 
Guitton \& Volle, 1987). Eye rotations indeed precede head movements, and eye- and head movements are more strongly coordinated in an HMD than in the real world (Pfeil et al., 2018). Thus, HMDs may produce better control over the presentation of stimuli in the visual field compared to rehabilitation systems using a monitor at a fixed position.

A.
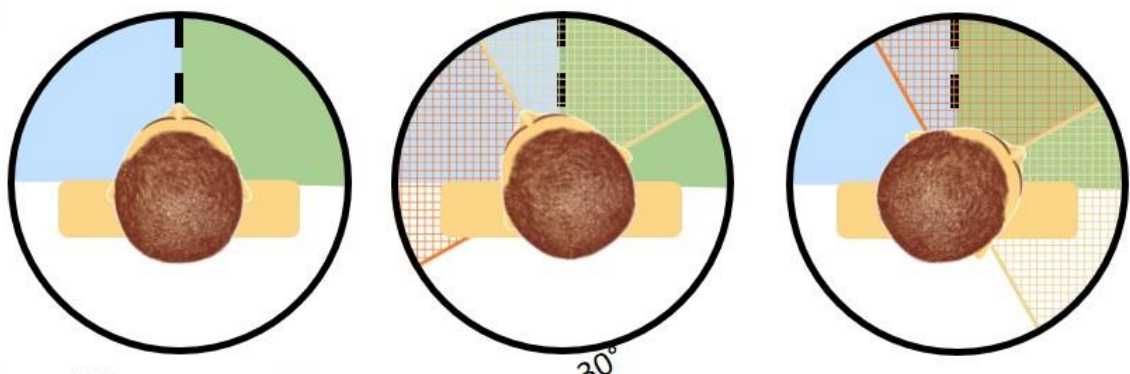

Left trunk space

Right trunk space

Left head space

Right head space

B.
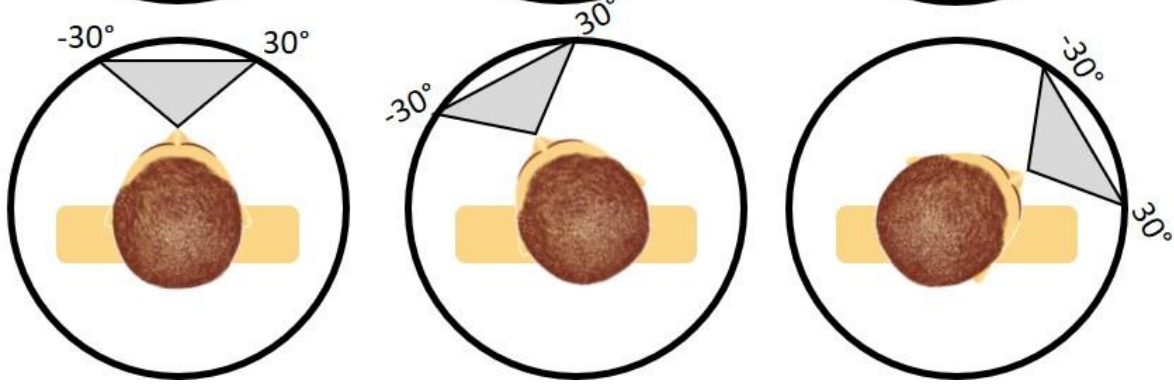

Figure 2. Schematic representation of different spatial reference frames relative to the trunk and head (A) and positioning target stimuli in the visual field corrected for head rotation (B).

\subsubsection{Serious games}

A second intervention principle is to use serious games. Researchers hope that they can leverage the motivational aspects of gaming to increase participation and engagement in rehabilitation tasks (Burke et al., 2009). Indeed, research in stroke rehabilitation has shown positive effects of gamified feedback on patient's motivation and recovery of hemiplegia (Popović et al., 2014). Moreover, serious games may allow patients to complete longer training sessions, as stroke patients reported less fatigue using a robotic device when they could use it to navigate a virtual plane than when they used the robotic device without such feedback (Mirelman et al., 2009). A recent meta-analysis confirmed that serious games were more effective at promoting post-stroke recovery of motor functions compared to conventional rehabilitation (Taut et al., 2017). For this reason, we gamified our rehabilitation tasks. However, at the moment, there is a lack of evidence-based guidelines for designing serious games for stroke patients, as there is little research that compares the effects of different serious game features on motivation and treatment efficacy (Taut et al., 2017). Thus, which features make serious games effective for rehabilitation in the stroke population remains unclear. 
Immersive VR Neglect Rehabilitation

\subsubsection{Patient-tailored contralesional stimulation}

A third intervention principle is to stimulate the contralesional side of space more frequently than the ipsilesional side of space. Since the severity of the spatial attention bias may vary across patients (Rorden \& Karnath, 2010), we tailored the stimulus presentation to each patient. To accomplish this, the spatial attention distribution was first measured in the VR environment. Then, a logistic model was fitted on the performance of the patient following the approach of Chatterjee et al. (1999). Based on this model, stimuli were positioned in a patient-tailored way during rehabilitation.

\subsubsection{Peripheral salient informative cues}

A fourth intervention principle is to use peripheral informative multisensory looming cues to promote endogenous and exogenous spatial attention orientation towards the contralesional side of space. Previous studies have identified several factors that can modulate the spatial bias in neglect patients. For instance, patients were slightly faster to detect contralesional targets when targets were more likely to appear on the contralesional side of space compared to when targets were equally likely to appear on the contra- and ipsilesional side of space (Geng \& Behrmann, 2006; Shaqiri \& Anderson, 2012). Bartolomeo et al. (2001) used a Posner paradigm in which the cue only occurred on the same side of the visual field (i.e., valid) in $20 \%$ of trials and on the other side (i.e., invalid) in $80 \%$ of trials. In this paradigm it is expected that observers orient away from the cued location. In this experiment, neglect patients were faster to detect contralesional targets preceded by an ipsilesional cue compared to trials in which contralesional targets were preceded by a contralesional cue. Moreover, there was no difference in response times to contralesional and ipsilesional targets for the invalid-cued trials (Bartolomeo et al., 2001). Hence, endogenous (top-down) orientation towards the contralesional field can be facilitated in neglect patients.

Bottom-up cues can also increase the chance to detect contralesional stimuli. For example, neglect patients detected a flash of light in the contralesional field more frequently when it occurred at the same spatial location and at the same time as an auditory beep (Frassinetti et al., 2002). Moreover, an expanding (looming) stimulus was more often detected than a contracting stimulus in the contralesional field during bilateral simultaneous stimulation (Dent \& Humphreys, 2011).

In sum, informative peripheral cues can promote endogenous orientation and audiovisual and looming signals can exogenously attract attention towards the contralesional side of space in neglect patients. For this reason, we used peripheral informative audiovisual looming cues to promote endogenous and exogenous spatial attention orientation towards the neglected side of space in our rehabilitation game. 


\subsubsection{Partial reinforcement}

A fifth principle is to use partial reinforcement. Non-human animal research has shown that behavioural change was more persistent after training when animals were not reinforced for their behaviour on each trial (i.e., partial reinforcement). Moreover, the persistence of the behavioural change increased as the percentage of trials on which a reward was provided reduced (Robbins, 1971). This principle has also been applied in clinical contexts. For instance, biofeedback training has more persistent effects after training with partial as compared to continuous reinforcement schedules (Parnandi \& Gutierrez-Osuna, 2018). Moreover, it has been hypothesized that partial reinforcement, better known as the virtual skinner box in the game world, is one of the key ingredients of why games are motivating and even addictive (Ducheneaut et al., 2006; Richter et al., 2015; Wilkinson, 2016).

\subsubsection{Continuous monitoring and alerting cues}

Patients with hemispatial neglect also frequently have non-spatial impairments, such as a reduced sustained attention and alertness (Husain \& Rorden, 2003; Van Vleet \& DeGutis, 2013). Researchers have proposed that rehabilitation of hemispatial neglect is more effective when rehabilitation also targets non-spatial impairments (Husain \& Rorden, 2003; Robertson et al., 1998; Van Vleet \& DeGutis, 2013). Some researchers have used non-spatial training methods in neglect patients. For instance, one study used a computerized training in which patients drove a virtual car on a road as quickly as possible. To avoid obstacles, patients had to press one key to drive the car and another key to stop the car, requiring them to sustain their attention on this repetitive task. Performance on clinical neglect tasks improved in chronic neglect patients after a 3-week training, but did not remain stable after discontinuation of training (Thimm et al., 2006). Later, this training approach was combined with optokinetic stimulation targeting the spatial component of neglect, but this combined approach did not generate better treatment results (Sturm et al., 2013).

In another study, patients completed a computerized training with a task in which visual scenes were presented with a variable inter-trial-interval. Patients had to press a button when they saw a scene and withhold their response for one specific target scene that occurred in $10 \%$ of the trials. This training approach resulted in more improvement in neglect symptoms than a visual search training (DeGutis \& Van Vleet, 2010). Thus, a training task in which patients have to continuously monitor the environment for unpredictable events may promote recovery of hemispatial neglect (Van Vleet \& DeGutis, 2013). In line with this research, we used a variable inter-trial-interval in our rehabilitation game so that patients would have to continuously monitor the virtual environment for targets and presented audiovisual alerting signals when patients did not respond to a target. 


\subsection{CURRENT STUDY}

In sum, we hypothesized that a combination of the seven abovementioned intervention principles could be effective in the rehabilitation of hemispatial neglect. In the current study, we present pilot results that were gathered throughout the game development process. First, we evaluated the safety and usability of our VR game. To this end, we compared cybersickness complaints before and after exposure to the VR game in six stroke patients. Second, we assessed multiple aspects of the user experience (i.e., usability, presence, motivation) through a questionnaire. In addition, four stroke patients played our VR game for multiple sessions in order to perform a preliminary assessment of our game design. More specifically, we tested whether neglect symptoms in the VR game corresponded to neglect symptoms on a computerized cancellation task. We evaluated the effect of the multisensory cue on performance. Finally, we tested the effect of two different game algorithms to tailor the sensory stimulation to the patient's neglected visual field.

\section{GAME DESIGN}

We made several adjustments to our game throughout the development process. An overview of the main differences between game versions is included in Supplementary Table S2. Here we present the design of the most recent version. The game design is also illustrated in a supplementary video (https://doi.org/10.6084/m9.figshare.6194591.v2).

\subsection{Apparatus}

We used the Oculus Rift CV1 (Oculus Rift / Oculus, n.d.) (Figure 3A). The Oculus Rift headset uses an OLED panel for each eye, each having a resolution of 1080 by 1200 pixels with a refresh rate of $90 \mathrm{~Hz}$ and a field of view of $110^{\circ}$. Integrated headphones can provide real time 3D audio effects. There are two infrared sensors that provide full rotational and positional tracking in a $1 \mathrm{~m}^{2}$ area. The right Oculus Touch Controller was used to provide responses (Figure 3B). A 3D printed cap in plastic was placed on top of the Oculus Touch Controller to cover the Oculus Home Button to prevent accidental button presses. Moreover, the soft side of a Velcro sticker was pasted on button B so that patients could more easily discriminate buttons A and B (Figure 3B). The VR game was developed in Unity 3D using the Oculus integration package. Code was written in C\#. Data of game events are stored in a local SQL database. The application runs on a Windows computer. 
A.

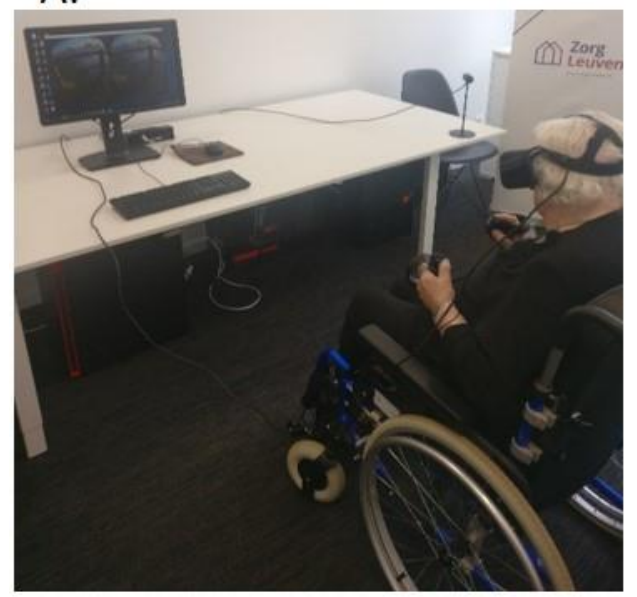

B.
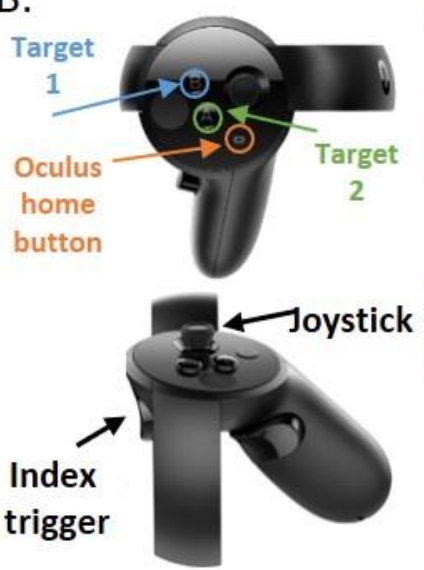

C.
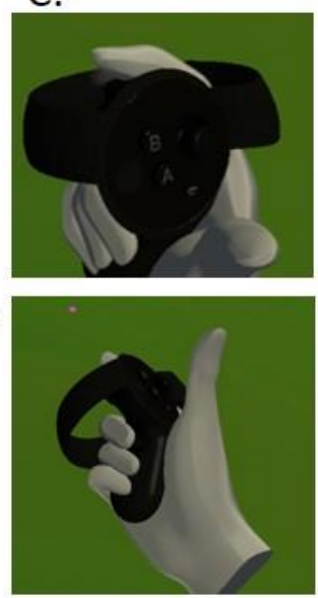

D.
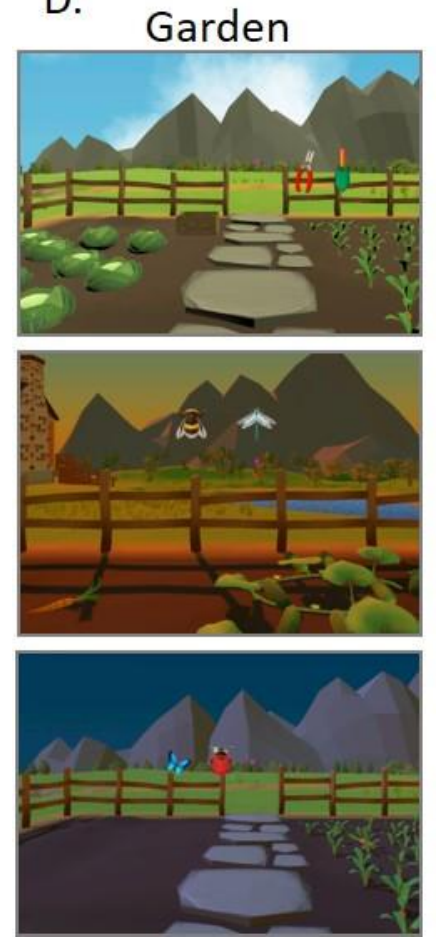
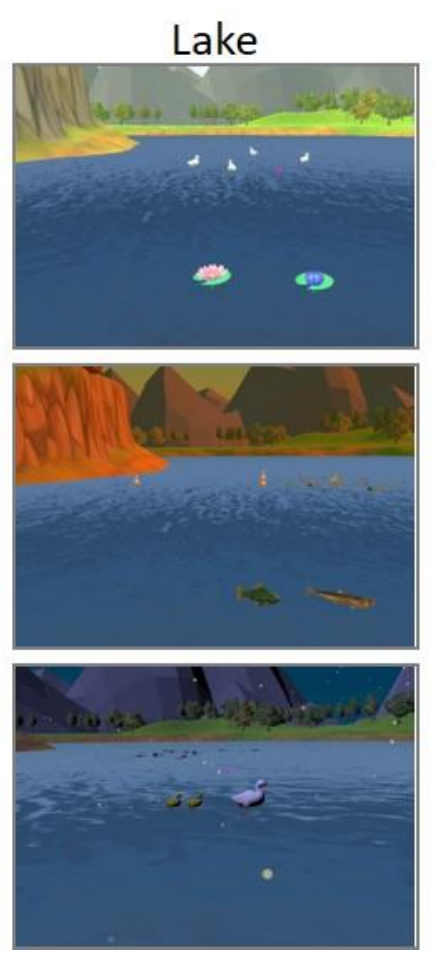

Forest
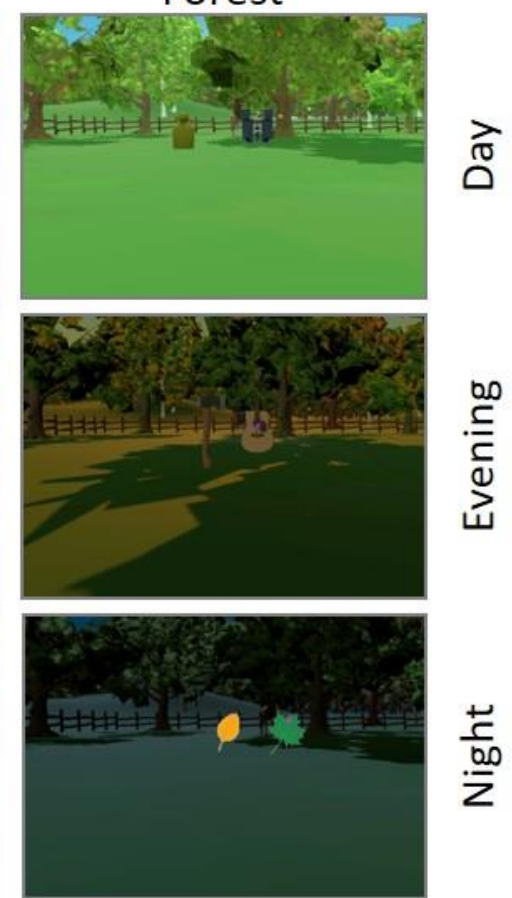

Figure 3. A patient wearing the Oculus Rift headset and holding the touch controllers (A). Note that, in contrast to the picture, patients only held the right touch controller and the left touch controller was disabled. The right touch controller (B). Note that a 3D printed cap was placed on top of the controller which blocked the functionality of the Oculus Home Button. The virtual model of the hand and right touch controller that patients saw in the VR environment (C). Scenes and target stimuli of 9 of the 18 levels (D).

\subsection{USER INTERFACE AND INTRODUCTION TO USING THE TOUCH CONTROLLERS}

The clinician logged into the application through a graphical user interface on the computer monitor. Afterwards, the game started in the VR environment. While the participant wore the headset, the clinician could see the game events on the computer monitor. Instructions were presented via short written text dialogs. They were presented until the participant pressed a button to continue. The text displays and buttons were presented in the centre of the visual field and for each button there was an 
icon and short text that indicated the functionality of the button. Moreover, to facilitate reading the text instructions, starting on the left side, each word in the instructions changed colour sequentially in the reading direction for 1 second coinciding with a short clicking sound.

First, the use of the touch controllers was taught to patients in a separate half-hour game session. Patients saw a virtual representation of their hand holding the controller in the VR environment (Figure $3 C$ ) and a picture of the controller was shown with the relevant button indicated. Patients were instructed to press the button. If the patient pressed the correct button, feedback was presented to indicate that the patient did the task accurately. If the patient pressed two buttons simultaneously, the patient was instructed that they should only press 1 button. The patient had to complete the task accurately 10 times before learning to use a new button. The player was sequentially introduced to the use of the two buttons, index trigger and joystick on the right controller through this procedure (Figure 3B). After having practiced each of the button presses sequentially, the different button presses were practiced once more in randomized order.

\subsection{GAMEPLAY}

\subsubsection{Game world and narrative}

The game world consisted of a vegetable garden, lake and forest. We chose natural outdoor scenes, as they have previously been described as relaxing and have been positively experienced by individuals with dementia using a virtual environment (Bruun-Pedersen et al., 2016). Each of these three scenes were presented to patients with one of three lighting conditions: day, evening or night (Figure 3D). Each of these 9 combinations of scenes and lighting conditions were presented twice during the rehabilitation game, constituting 18 levels, with an option to start the game over. There was an additional assessment module of 3 levels encompassing the three scenes (i.e., garden, lake, forest), which did not differ from the rehabilitation scenes. The narrative of the game involved a good deeds theme, as research has shown that older adults are interested in this theme (De Schutter \& Vanden Abeele, 2008). The player was told that the farmer of the village became ill and needed help with, for example, maintaining his vegetable garden or watching his children. Before each level, the player was instructed on a specific task which was part of the storyline. When the entire game was completed, the player was informed that the farmer was no longer ill and that he was grateful for all the help he received from the patient.

\subsubsection{Stimuli}

The cue was a white or yellow transparent disk that changed size according to a looming function following the design of Parker \& Alais (2007). The size of the disk increased exponentially for $80 \%$ of the time and decreased in size according to a cosine function for $20 \%$ of the time with each cycle 
lasting 1s. A looming auditory cue was created by manipulating the amplitude of a pure $200 \mathrm{~Hz}$ tone according to the same looming function. The visual and auditory cue changed size or amplitude at the same frequency and in phase. For each game level, a pair of target stimuli was presented. The two target stimuli within each level differed in colour and shape, so that patients with object-centred neglect would be able to visually discriminate the two targets (Figure 3D). In some levels, the targets were $3 \mathrm{D}$ objects, while in other levels, the targets were $2 \mathrm{D}$ images. The location of the cue and the target were adjusted based on the orientation of the HMD at the start of the trial. That is, the cue and target were presented at a certain horizontal location relative to the HMD and rotated so that they faced the observer.

To ensure a patient-tailored game difficulty, we first assessed patient's individual spatial attention distribution in an assessment module. The assessment was performed once by patients before entering the rehabilitation module. In the assessment, target positions were sampled from a uniform distribution with a visual angle of $30^{\circ}$ in the left and right visual field, and a visual angle of $5^{\circ}$ in the upper and lower visual field. The game can be played under two conditions: active and placebo. For the active version of our game, a logistic regression model was estimated on the performance of patients in the assessment. This logistic regression model was mirrored along the $x$-axis to create a probability distribution of target locations, with a high probability of targets at those locations where patients missed many targets in the assessment (Figure 4A). This probability distribution was then used to sample target locations during the rehabilitation trials. For the placebo version of the game, target events were sampled from a uniform distribution centred on $0^{\circ}$ of the visual field with a horizontal angle of $1.5^{\circ}$ in the left and right visual field and a vertical visual angle of $5^{\circ}$ in the upper and lower visual field. All other game aspects were identical between these two conditions. 

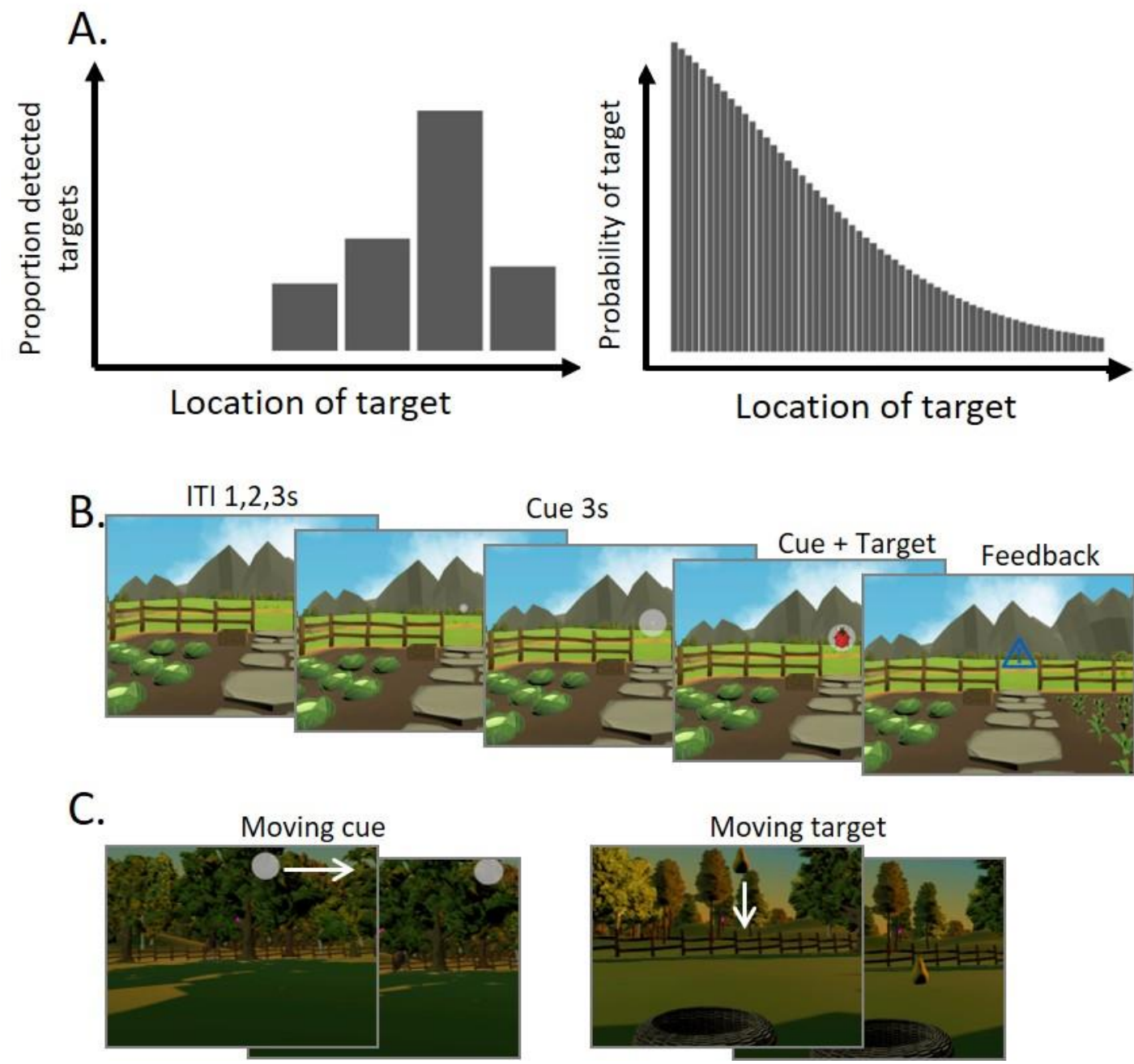

Cue 3s
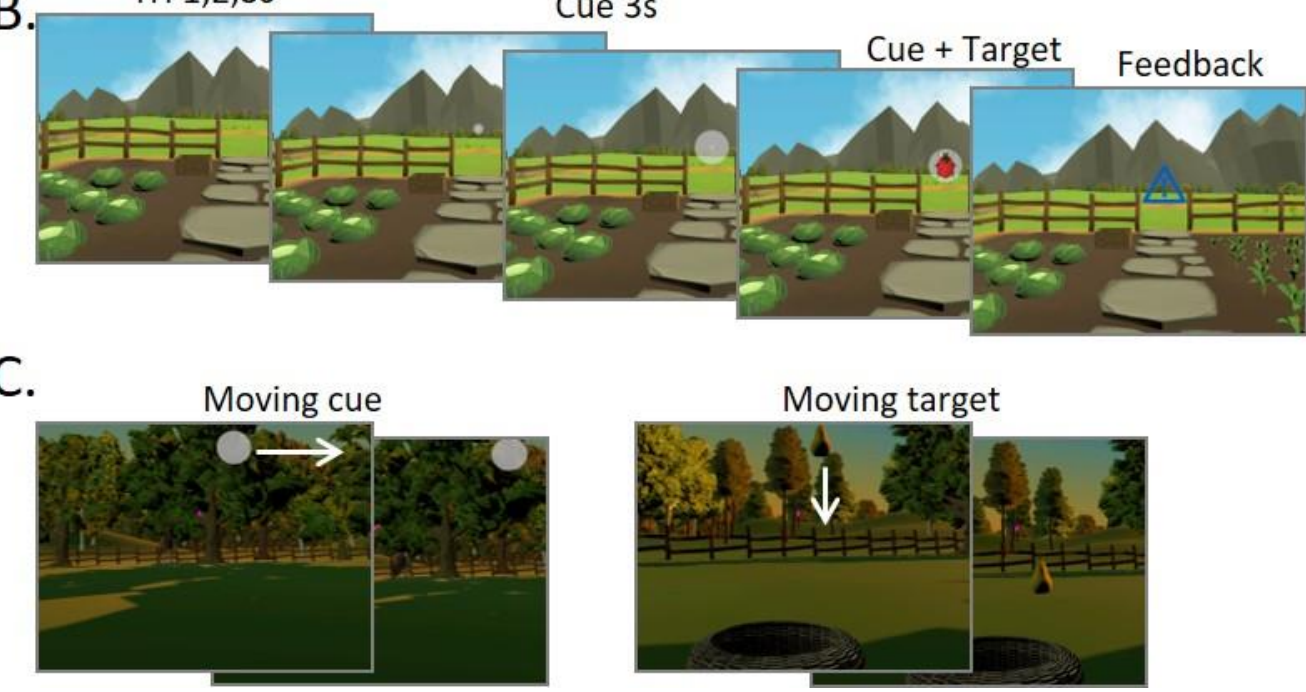

Figure 4. Illustration of patient-tailored design (A) and design of the tasks (B, C). If patients detect less targets for the left visual field during the assessment (panel $A$, left figure), than the probability that a target appears at those locations was higher during rehabilitation (panel A, right figure). In Task 1 (panel B), a cue was presented for $3 \mathrm{~s}$ in $50 \%$ of trials. Then, the target and cue were presented for $3 \mathrm{~s}$ or until a response was provided. Afterwards, feedback was presented. In Task 2 (panel B), the cue moved towards a location after being presented in the centre of the visual field for 3 seconds and the target was presented without the cue and moved downward.

\subsubsection{Task}

The game consisted of two variations of a visual discrimination task (Figure 4). A cue was presented in $50 \%$ of the trials, which always predicted the location of the target. Then, a target was presented in front of the cue. The target stimulus was presented for $3 \mathrm{~s}$ or until a response was provided. There were two types of target stimuli for each level. The patient was asked to report which target stimulus was presented by pressing the corresponding button. The target-response mapping was practiced before the start of each level.

If the patient pressed the correct button, a green checkmark was presented to signal that the response was correct. If the patient pressed the wrong button, a red cross was presented. If no response was provided within the response time window, a blue exclamation mark accompanied by a sound was 
presented. In $25 \%$ of trials in which the patient gave an accurate response, an audio-visual reward was presented. Feedback and reward stimuli were presented for $1 \mathrm{~s}$. All feedback and reward stimuli were presented in the centre of the visual field with their position and orientation adjusted according to the orientation of the HMD in real-time. In between trials, there was an interval in which no events took place. The duration of this interval could be equal to 1,2 or $3 \mathrm{~s}$ with equal probability.

In Task 1 (i.e., non-moving cue/target), the cue was presented for a fixed duration of 3s. Afterwards, a target was presented. In Task 2 (i.e., moving cue/target), the cue was first presented for $3 \mathrm{~s}$ in the centre of the visual field and then moved from the centre of the visual field to the target location at a constant speed (Figure 4C). For more peripheral target locations, the cue was presented for a longer time period. Once the cue reached the target location, the cue disappeared and a target appeared. The target moved downward until it reached the floor or until the patient gave a response. The speed at which the target moved towards the floor was determined by the distance of the target stimulus to the floor so that it always reached the floor after a fixed duration of 3 seconds. Once the object collided with the floor, which coincided with the end of the response time window, the patient could no longer respond to the target.

\subsubsection{Level design}

The game consisted of 18 levels. The levels were presented in a fixed order. Each three levels constituted 1 day. The lighting conditions of the scenes were always presented in the order of day evening - night. Each level was finished once a patient had accumulated sufficient points. Points were awarded with a $25 \%$ probability per correct trial. To ensure that patients would not advance too slowly through the game, points were scaled as a function of their performance, using the formula (1/performance)/reward probability, in which performance refers to the proportion accurate responses. The score they received for a correct response was updated using this formula every 10 trials. If patients did not provide any correct responses in these 10 trials, performance was set to 0.05 . Before each level, patients received the opportunity to practice the task of the next level. Progress in the game was saved and patients could play further the next session. Before entering the 18 gamelevels, patients were assessed in a block of 3 assessment-levels. This assessment was performed once before the rehabilitation module started. In the assessment, each level finished after a fixed number of 75 trials. Moreover, no rewards were presented and the assessment trials needed to be completed within a single session. 


\section{GAME DEVELOPMENT}

We followed the guidelines for designing usable systems, which emphasize the importance of observing participants using early prototypes of the system, iteratively fixing usability issues and retesting the system (Gould \& Lewis, 1985). We iterated through multiple versions of our game design (Supplementary Table S2), optimizing the design on the basis of observations made during pilot testing in several phases. All patients played the active version of our game. Phase 1 and 2 were designed to optimize the user interface and observe usability issues, while Phase 3 aimed to evaluate usability and user experience over a longer user period and to validate certain game mechanisms.

\subsection{PARTICIPANTS}

In Phase 1, a convenience sample of 15 neurologically healthy individuals used our VR game at an open science event. The age of 12 of these 15 participants is known and was on average 44 years (SD $=19$, Range: $23-75$ ). The gender of 10 participants is known ( 6 female). We recorded education levels of 11 participants and they all had a degree of higher education. Of the 15 participants, 11 had never used VR before the demo.

In Phase 2 and 3 we recruited 7 stroke patients (Table 2 ) in the rehabilitation centres UZ Leuven Pellenberg and RevArte. In Phase 2, there were no criteria regarding presence or absence of hemispatial neglect and in Phase 3 we asked clinicians to only refer hemispatial neglect patients. Clinical MRI or CT scans were used to delineate lesions with the Clusterize toolbox (de Haan et al., 2015) (Figure 5). Scans were normalized using age-specific CT and MRI templates (Rorden et al., 2012). All patients were screened for domain-specific cognitive impairments with the Dutch Oxford Cognitive Screen (OCS-NL) (Huygelier et al., 2019) (Figure 6) and the patients in Phase 3 were also screened for neglect (Table 3).

Individuals with a history of epilepsy, a medical implant such as a pacemaker, a craniotomy or severe visual acuity problems were excluded. Phase 1 was approved by the Social and Societal Ethics Committee of the KU Leuven (G-2017 11 988). Phase 2 and Phase 3 were approved by the ethical committee for research of the UZ Leuven (S61410). All participants gave written informed consent. All study procedures respected the Helsinki declaration. 


\begin{tabular}{|c|c|c|c|c|c|c|c|c|}
\hline Patient & $\begin{array}{c}\text { Age } \\
\text { (years) }\end{array}$ & Gender & $\begin{array}{c}\text { Years of } \\
\text { education }\end{array}$ & $\begin{array}{l}\text { Handed- } \\
\text { ness }\end{array}$ & DSS & $\begin{array}{c}\text { Stroke } \\
\text { aetiology }\end{array}$ & $\begin{array}{l}\text { Lesion } \\
\text { side }\end{array}$ & $\begin{array}{l}\text { Pilot } \\
\text { phase }\end{array}$ \\
\hline P1 & 68 & $\mathrm{~F}$ & 15 & $\mathrm{R}$ & 72 & Ischemic & L & $2 a$ \\
\hline P2 & 61 & $M$ & 11 & $\mathrm{R}$ & 56 & Ischemic & $\mathrm{L}$ & $2 b$ \\
\hline P3 & 69 & $M$ & 18 & $\mathrm{R}$ & 113 & Ischemic & $\mathrm{R}$ & $2 b$ \\
\hline $\mathrm{P}^{*}{ }^{*}$ & 62 & $M$ & 10 & $\mathrm{R}$ & & & $\mathrm{R}$ & $3 a$ \\
\hline P5 & 48 & $M$ & 14 & $\mathrm{R}$ & 48 & Ischemic & $\mathrm{R}$ & $3 a$ \\
\hline P6 & 65 & $\mathrm{~F}$ & 17 & $\mathrm{R}$ & 129 & Ischemic & $\mathrm{R}$ & $3 b$ \\
\hline P7 & 44 & $M$ & 13 & $\mathrm{R}$ & 113 & Haemorrhagic & $\mathrm{R}$ & $3 c$ \\
\hline
\end{tabular}

Note. DSS $=$ days between stroke and first screening session. $R=$ right, $L=$ left. ${ }^{*}=$ no $C T$ or MRI scan nor radiologist protocol available, patient was admitted in a rehabilitation centre in the stroke unit.

Table 3. Neglect screening results

\begin{tabular}{cccccccccc} 
Patient & VF & VF & Hearts & Hearts & LC & LC & RS & RS & Figure \\
& $\mathbf{R}$ & $\mathbf{L}$ & Total & R-L & Total & R-L & Total & R-L & copy \\
\hline P1 & 2 & 2 & 49 & -1 & NA & NA & NA & NA & NA \\
\hline P2 & 2 & 2 & 44 & -4 & NA & NA & NA & NA & NA \\
\hline P3 & 2 & 2 & 41 & -1 & NA & NA & NA & NA & NA \\
\hline P4 & 2 & 0 & 11 & $\mathbf{8}^{+}$ & 36 & 2 & 35 & $\mathbf{1 1}^{+}$ & 1 \\
\hline P5 & 2 & 2 & 46 & 3 & 40 & 0 & 59 & $-1^{-}$ & 3 \\
\hline P6 & 2 & 0 & 30 & $\mathbf{8}^{+}$ & 37 & 1 & 53 & 3 & 1 \\
\hline P7 & 2 & 2 & 42 & 5 & 38 & 0 & 49 & -1 & 2 \\
\hline best score & $\mathbf{2}$ & $\mathbf{2}$ & $\mathbf{5 0}$ & $\mathbf{0}$ & $\mathbf{4 0}$ & $\mathbf{0}$ & $\mathbf{6 0}$ & $\mathbf{0}$ & $\mathbf{3}$ \\
\hline
\end{tabular}

Note. $\mathrm{VF}=$ confrontation task OCS-NL, Hearts $=$ OCS-NL hearts cancellation, $\mathrm{LC}=$ Behavioral Inattention Test Letter cancellation, RS = Weintraub Random Shape Cancellation, Figure copy = Behavioral Inattention Test figure copy task, NA = not administered. The difference in performance between left and right on the cancellation tasks was tested using a Bayesian contingency table test, with $+=\mathrm{BF}_{10}>3$ (evidence for dependency), $-=\mathrm{BF}_{10}<0.33$ (evidence for no dependency) and grey font $=\mathrm{BF}_{10} \in[0.33,3]$ (inconclusive evidence). 


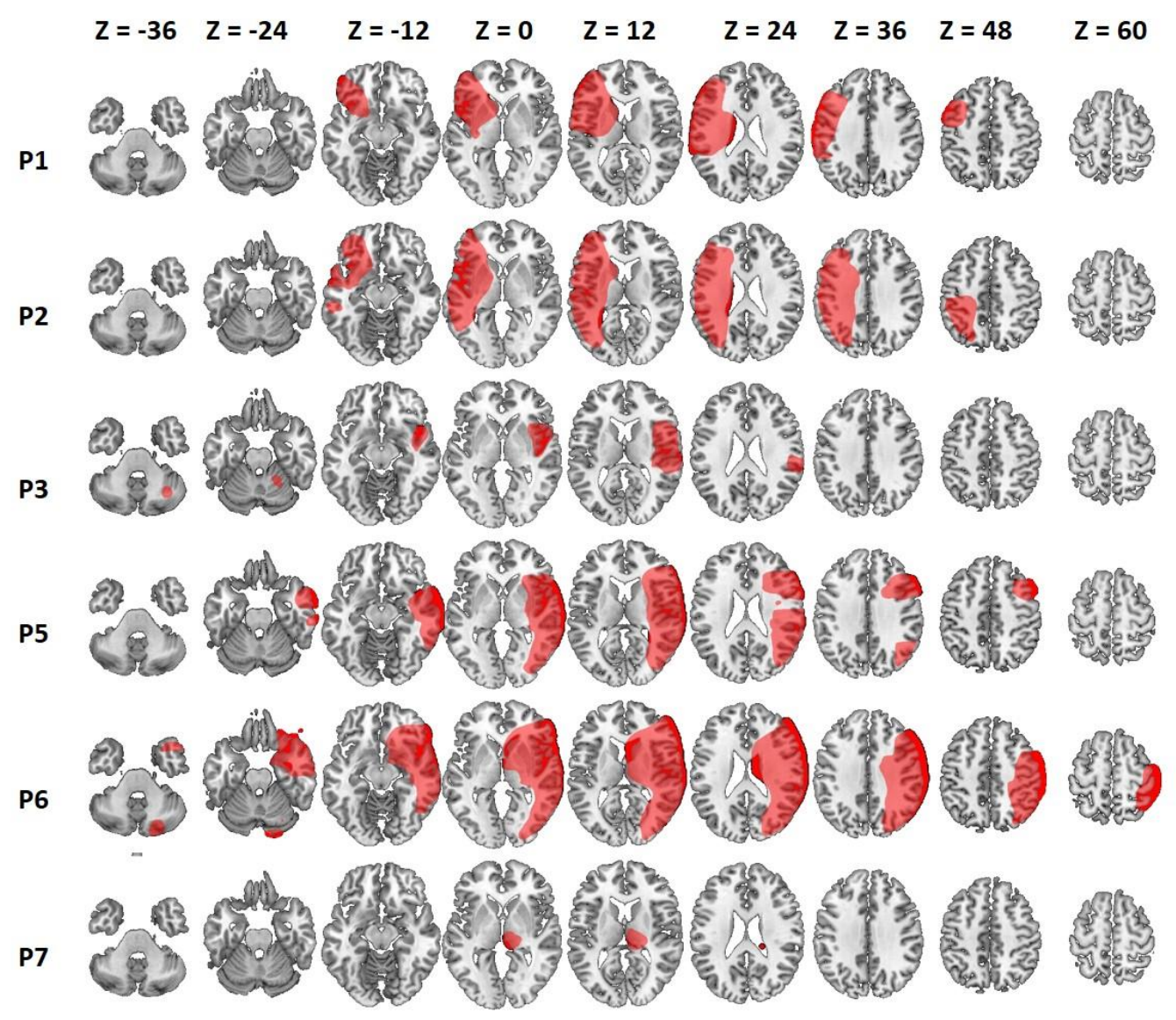

Figure 5. Lesion maps projected on axial slices of a T1-weighted MRI template in MNI space in neurological convention. Lesions were delineated on clinical Fluid Attenuated Inversion Recovery scans for P1, P2, P5, P6 and on clinical CT scans for P3 and P7. There was no MRI or CT scan available of P4.
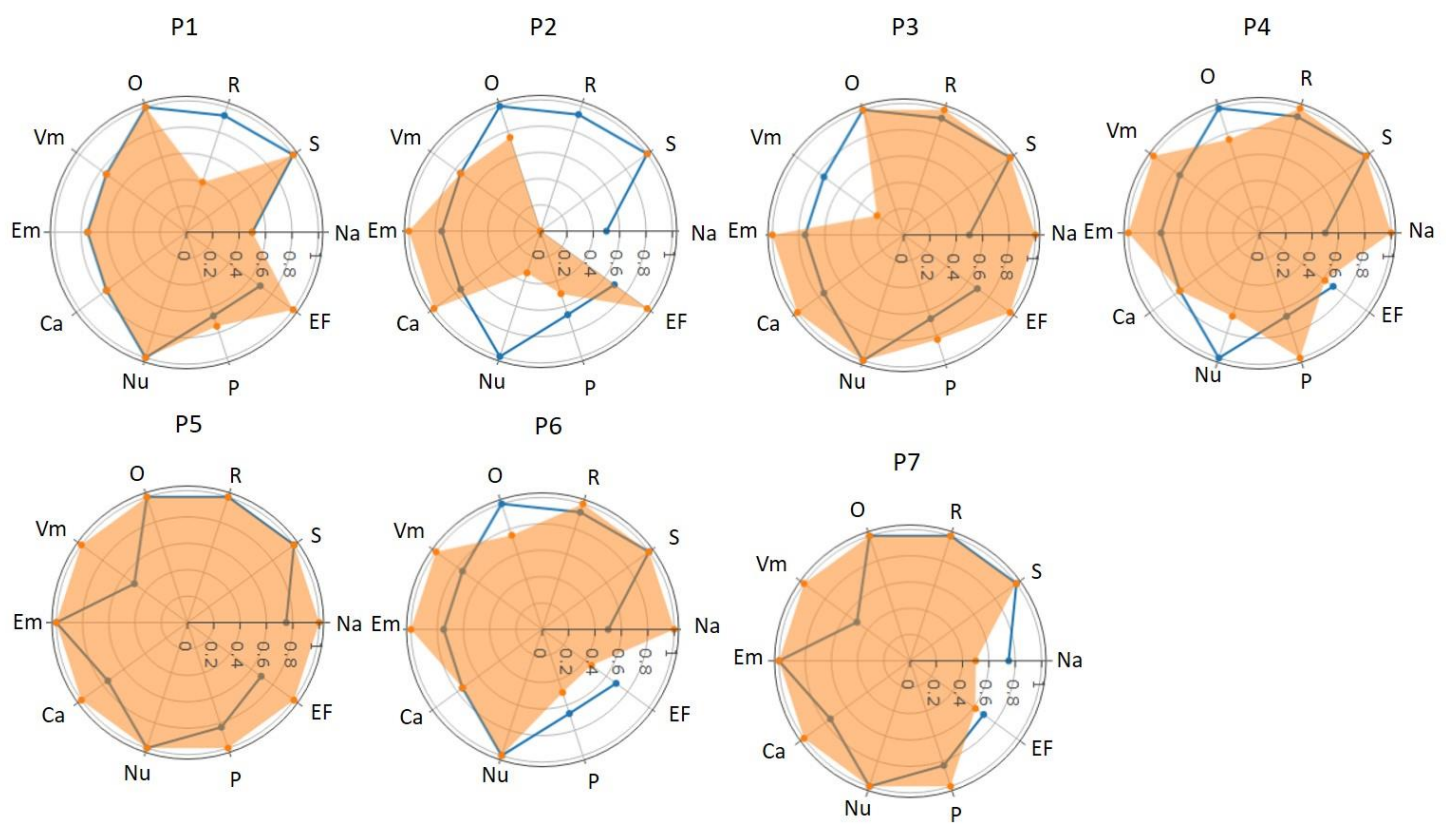

Figure 6. OCS-NL profiles. The blue line represents age-adjusted $5^{\text {th }}$ percentiles of a neurologically healthy group from Huygelier et al. (2019). The surface represents test scores of patients (proportion correct). $\mathrm{R}=\mathrm{reading}, \mathrm{S}=$ semantics, $\mathrm{Na}=$ naming, $\mathrm{EF}=$ executive functions, $\mathrm{P}=$ praxis, $\mathrm{Nu}=$ numeric cognition, $\mathrm{Ca}=$ calculation, $\mathrm{Em}=$ episodic memory, $\mathrm{Vm}=$ verbal memory, $\mathrm{O}=$ orientation. 
Immersive VR Neglect Rehabilitation

\subsection{MATERIALS}

\subsubsection{Neuropsychological assessment}

In Phase 2 and 3, we administered a battery of validated pen-and-paper neuropsychological tests in order to characterize the cognitive profiles of the included stroke patients. The Dutch version of the Oxford Cognitive Screen (OCS-NL) is a stroke-specific screen that measures impairments in 5 domains: language, numeric cognition, memory, praxis and executive functioning / attention. Receptive language impairments were assessed with the subtest semantics, while expressive language impairments were assessed with the naming and reading subtests. Numeric cognition involved one subtest in which patients wrote numbers that were read aloud (i.e., numbers) and another subtest in which patients performed additions and subtractions (i.e., calculation). Memory was assessed through recognition of verbal (i.e., verbal memory) and episodic content (i.e., episodic memory). Praxis was assessed through imitation of meaningless gestures. Executive functioning was assessed with a taskswitching test and attention was assessed using a cancellation task with 50 targets and 150 distractors. Moreover, visual field was assessed with a simple visual confrontation test. Age-adjusted norms were used to interpret test scores (Huygelier et al., 2019). In addition, in Phase 3, we administered the Behavioral Inattention Test (BIT) letter cancellation task and figure copy task (Cermak \& Hausser, 1989). In the letter cancellation task, patients cancelled each letter " $E$ " and " $R$ " in rows of letters with a total of 40 target letters presented on an A4 paper in landscape orientation. In the figure copy task, patients copied three drawings. If important parts of the drawing were missing, the copy was scored a zero, with a total of 3 as the best possible score. The Weintraub cancellation task is a cancellation task with 60 target shapes embedded among 300 distractors presented on an A4 paper in landscape orientation (Weintraub \& Mesulam, 1988).

\subsubsection{Computerized cancellation task}

In Phase 3, we also administered a computer version of a cancellation task on a monitor with a resolution of 1920 by 1080 pixels. Patients were seated at a distance of approximately $70 \mathrm{~cm}$ from the monitor without a chin rest. Patients had to give responses by clicking the left mouse button. Code was written in Python 2.7 using Psychopy 1.90.3 for stimulus presentation and response registration. Targets (i.e., full-outlined hearts) and distractors (i.e., hearts with left or right gap) were presented in a grid with a width of $28 \mathrm{~cm}$ and a height of $18 \mathrm{~cm}$. At a distance of $70 \mathrm{~cm}$, stimuli were placed within a horizontal angle of $11^{\circ}$ to the left and right side and within a vertical angle of $7.3^{\circ}$ to the upper and lower side. Stimuli were located in the grid at 15 horizontal locations of which their position relative to the centre of the screen were: $-13.01,-11.2,-9.33,-7.47,-5.6,-3.73,-1.87,0,1.87,3.73,5.6,7.47$, 9.33, 11.2 and $13.01 \mathrm{~cm}$. Stimuli were located at 10 vertical locations: $-8.1,-6.3,-4.5,-2.7,-0.9,0.9$, 
$2.7,4.5,6.3$ and $8.1 \mathrm{~cm}$. The stimuli that were placed in the cells had a size of $0.9 \mathrm{by} 0.9 \mathrm{~cm}$. The location of the stimuli was based on these 150 locations, but a random amount of jitter was added to make the search array disorganized with a maximum displacement of $0.45 \mathrm{~cm}$.

For each trial, 50 targets and 100 distractors were presented. The target stimuli were spread randomly across the cells for each trial. Every three trials, a break was presented. Each trial was presented for a maximum duration of 4 minutes or until patients indicated that they had finished the task by pressing the space bar. The patient was instructed to click on the targets. Once a target had been clicked, a blue line appeared on the target. A total of 12 trials were presented. One practice trial was presented, in which feedback was provided. When the patient clicked on a target stimulus, a green " $\mathrm{V}$ " sign appeared and a $400 \mathrm{~Hz}$ tone was presented during $150 \mathrm{~ms}$. When the patient clicked on a distractor stimulus, a red " $\mathrm{X}$ " sign appeared and a $200 \mathrm{~Hz}$ tone was presented during $150 \mathrm{~ms}$.

\subsubsection{Questionnaires}

Cybersickness was measured with the Simulator Sickness Questionnaire (SSQ $)^{41}$ that was translated to Dutch by our research team. Each of the 16 SSQ items were rated on a scale with four levels representing no, mild, moderate or severe discomfort.

In Phase 1 and 2, we asked participants to evaluate different aspects of the game design using a 23item User Experience scale with items rated on a 5-point Likert scale going from totally disagree (1) to totally agree (5) with 3 as a neutral midpoint. Participants were asked questions about the usability of the touch controllers and user interface, the amount of presence they experienced, their experience of the narrative and their motivation. The questions about the narrative were translated to Dutch based on the Narrative Engagement Scale (Busselle \& Bilandzic, 2009). The motivation items were based on the intrinsic motivation inventory (McAuley et al., 1989) taxing interest and enjoyment, while the presence items were translations of the International Test Commission Sense of Presence Inventory items (Lessiter et al., 2001). In Phase 3, the items regarding the user interface and the narrative were not administered.

\subsection{DESIGN AND PROCEDURE}

Phase 1 and 2 were designed to optimize the user interface and observe usability issues, while Phase 3 aimed to evaluate usability and user experience over a longer period and to validate certain game mechanisms (Figure 7). In Phase 1 and 2, participants played the game for a single session. In Phase 1, after a short experience with the game, the User Experience scale and SSQ were administered (Figure 7A). In Phase 2, we first performed a general screening of patients (Figure 7B). In the general screening we administered a semi-structured interview about their health and demographic characteristics, and then administered the OCS-NL. Then, in a second session, patients played the VR game. In this session, 
the SSQ was first administered, then the VR game was played and afterwards the User Experience scale and SSQ were administered. In Phase $2 b$, patients played two versions of the game, each in one session (Figure 7C). In Phase 3, we added a neglect screening session and patients played the game for 6 sessions spread across 6 workdays, playing approximately 3 levels per session (Figure 7D). In each of these game sessions, patients were asked whether they liked the game in general and whether they experienced any physical discomforts. Throughout these pilot phases, we iterated through multiple game versions (Figure 7E, Supplementary Table S2). The design of the first version (i.e., v1.3) is described elsewhere (Huygelier et al., 2017).
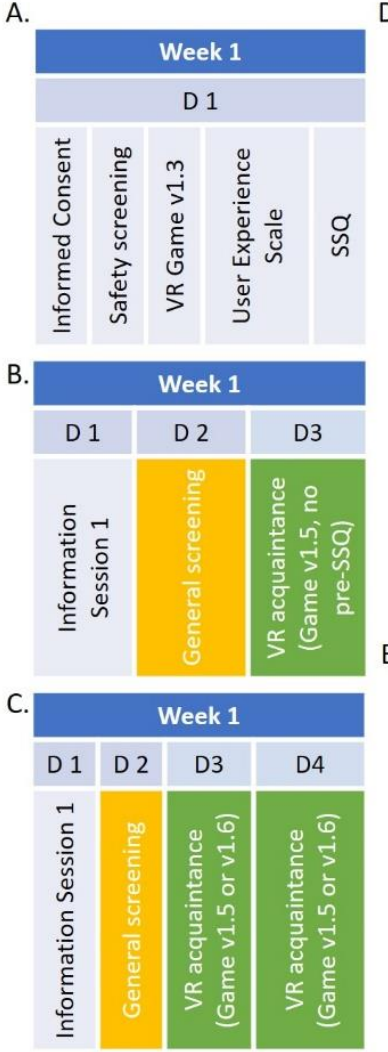

D.

\begin{tabular}{|c|c|c|c|c|c|c|c|c|c|c|c|}
\hline \multicolumn{5}{|c|}{ Week 1} & \multicolumn{5}{|c|}{ Week 2} & \multicolumn{2}{|c|}{ Week 3} \\
\hline D 1 & D 2 & D & D 4 & D5 & D 1 & D 2 & D 3 & D 4 & D 5 & D1 & D2 \\
\hline 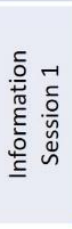 & 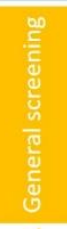 & 9 & 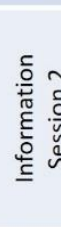 & 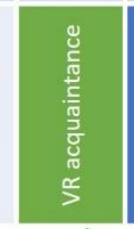 & 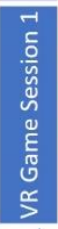 & 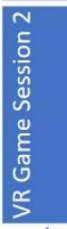 & 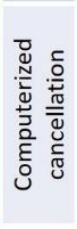 & 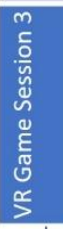 & 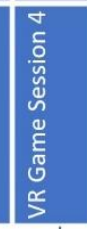 & 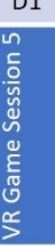 & 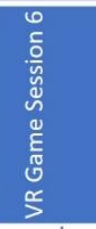 \\
\hline \multicolumn{3}{|c|}{$\begin{array}{l}\text { 1. Health } \\
\text { questionnaire } \\
\text { 2. Safety } \\
\text { screening } \\
\text { 3. OCS-NL }\end{array}$} & \multicolumn{2}{|c|}{$\begin{array}{l}\text { 1. BIT letter } \\
\text { cancellation } \\
\text { 2. BIT Figure Copy } \\
\text { 3. Random shape } \\
\text { cancellation }\end{array}$} & \multicolumn{4}{|c|}{$\begin{array}{l}\text { 1. SSQ pre } \\
\text { 2. VR introduction } \\
\text { 3. User experience } \\
\text { 4. SSQ post }\end{array}$} & \multicolumn{3}{|c|}{$\begin{array}{l}\text { 1. VR Game } \\
\text { 2. Physical } \\
\text { discomforts? } \\
\text { 3. Did you like the } \\
\text { game today? }\end{array}$} \\
\hline \multicolumn{2}{|c|}{ Pilot phase } & \multicolumn{2}{|c|}{ Goal } & \multicolumn{2}{|l|}{ Sample size } & \multicolumn{2}{|c|}{ Sample } & \multicolumn{2}{|r|}{ Game } & \multicolumn{2}{|c|}{$\begin{array}{c}\text { Game session } \\
\text { duration }\end{array}$} \\
\hline \multicolumn{2}{|c|}{1} & \multirow{3}{*}{\multicolumn{2}{|c|}{$\begin{array}{l}\text { Usability and } \\
\text { safety }\end{array}$}} & 15 & & \multicolumn{2}{|c|}{$\begin{array}{l}\text { Healthy } \\
\text { controls }\end{array}$} & \multicolumn{2}{|r|}{ v1.3 } & \multicolumn{2}{|c|}{20 minutes } \\
\hline \multicolumn{2}{|c|}{$2 a$} & & & \multicolumn{2}{|l|}{1} & \multirow{5}{*}{\multicolumn{2}{|c|}{$\begin{array}{c}\text { Stroke } \\
\text { patients }\end{array}$}} & & v1.5 & \multirow{2}{*}{\multicolumn{2}{|c|}{30 minutes }} \\
\hline & & & & 2 & & & & & v1.6 & & \\
\hline & & \multirow{3}{*}{\multicolumn{2}{|c|}{$\begin{array}{l}\text { Preliminary } \\
\text { validation } \\
\text { game design }\end{array}$}} & 2 & & & & & v1.7 & \multirow{3}{*}{\multicolumn{2}{|c|}{45 minutes }} \\
\hline & & & & 1 & & & & & v1.8 & & \\
\hline & & & & 1 & & & & & 1.9.2.1 & & \\
\hline
\end{tabular}

Figure 7. Overview of pilot phases. Pilot phase 1 (A), Pilot phase 2a (B), Pilot phase 2b (C), Pilot phase 3 (D). Overview of patient samples, game versions and duration of game sessions per pilot phase (E).

\subsection{DATA-ANALYSIS}

\subsubsection{Cybersickness and user experience}

To summarize results of the cybersickness questionnaire, we averaged the ratings of participants across the 16 items of the SSQ scale. We visualized and reported descriptive statistics of the average SSQ scores. Additionally, we estimated a Bayesian model with the BayesFactor package (Rouder et al., 2009) treating each individual SSQ item as repeated measures within participants, to evaluate whether there was a difference in SSQ scores before and after VR exposure in the six stroke patients who 
completed the pre- and post SSQ questionnaire. For the user experience scale, we averaged ratings across items per subscale.

\subsubsection{Game data}

\subsubsection{Correspondence of spatial attention impairment between computer and VR tasks}

We first evaluated whether the spatial attention impairment of patients could be detected with our VR rehabilitation game. To this end, we tested whether there was an interaction of the target location (i.e., left versus right visual field) and the task used to measure performance (i.e., computerized cancellation task, VR rehabilitation task with moving cue and target, and VR rehabilitation task without moving cue and target). These three conditions differ in many aspects, such as the distribution of target locations, the response time limit, type of stimuli used, number of trials, presence of distractor stimuli. Thus, this comparison cannot clarify which aspects may lead to differences, but it can reveal whether our VR task is able to pick up on the spatial attention impairment of the patients who we tested. To test this hypothesis, we performed a Bayesian logistic regression analysis with the brms package (Bürkner, 2017). We performed these analyses per patient as each patient played a different version of the game.

\subsubsection{Effect of cue and target location on performance}

Additionally, we tested whether the cue in the VR rehabilitation game affected performance. We predicted that patients would detect more targets in the cued than uncued trials. Moreover, we predicted that the cue would also improve target detection in the contralesional (i.e., left) visual field. In addition, we tested whether the cue had the same effect in the VR rehabilitation task in which the cue moved versus when the cue did not move. Note that the VR environment was not independent of this task condition. That is, we only presented the task with the moving cues and targets in the forest scene and the task with non-moving cues and targets in the garden and lake scenes. Thus, differences between these conditions can reflect a mix of multiple aspects. To test our predictions, we performed a Bayesian logistic regression analysis including the interaction of target location (i.e., left versus right visual field), the presence or absence of the cue and the type of task (i.e. moving cue/target, nonmoving cue/target). We performed these analyses per patient as each patient played a different version of the game.

\subsubsection{Patient-tailored design}

One of our intervention principles is to present target stimuli more frequently at those locations where patients did not detect targets in the VR assessment. If our game algorithm worked, the target locations in the rehabilitation game should be biased more towards the contralesional side of space for patients who have a more severe spatial attention impairment. 
In the game played by patients P4 and P5, we adjusted target locations throughout the game based on the average location of undetected targets in the 5 most recent trials (i.e., Centre of Cancellation (COC) algorithm). In the game played by patients P6 and P7, we first assessed the spatial attention impairment, then fitted a logistic model on their performance and used this logistic model to sample the target locations (i.e., Logistic model algorithm). To evaluate which of these two algorithms worked best, we tested the interaction of algorithm and neglect status. If an algorithm worked better, the target locations should differ more between patients with versus without neglect. The neglect status was determined on the basis of whether patients showed a significant difference in cancellation performance between the left and right visual field on the computerized cancellation task. We chose this task to subdivide patients, as this task should produce more precise estimates of performance compared to clinical tasks due to the higher number of trials. Based on this task, P4 and P6 were assigned to the "neglect group" and P5 and P7 were assigned to the "no neglect group". These analyses were only done for the four patients who participated in Phase 3, as multiple game sessions were necessary to provide sufficient data to perform these analyses.

Moreover, as only 4 patients played the VR game for multiple sessions, we further assessed whether the two algorithms truly differed using Monte Carlo simulations. We simulated performance on the VR task using a simple binomial model of neglect, which is discussed in detail in Huygelier and Gillebert (2018). We simulated data for 4 patient cases who varied in the severity of the spatial (i.e., R-L difference, difference in probability to detect targets between left and right visual field) and nonspatial attention impairments (i.e., non-spatial errors). More specifically, the R-L differences were equal to $0.20,0.40$ and 0.60 . The non-spatial errors were equal to 0.20 or 0.40 . For each of these 4 cases and 2 patient-tailored algorithms, we simulated game data for 1000 repetitions. The location of target positions was determined by the patient-tailored algorithm and performance was simulated using the binomial model. Then, to obtain the expected value of the horizontal target positions, we averaged the simulated horizontal target positions across the 1000 repetitions.

\section{RESULTS}

\subsection{CYBERSICKNESS}

Of the 15 healthy participants, 1 participant reported severe discomfort on the SSQ item "fullness of the head" and 2 participants reported severe discomfort on the SSQ item "blurry vision" after VR exposure. The average ratings across all items were low after VR exposure in healthy participants (M $=0.25, \mathrm{SD}=0.42$, Range: $0-1.62$, Figure $8 \mathrm{~A})$. We did not assess SSQ symptoms before VR exposure in healthy participants. None of the stroke patients reported severe physical discomforts on the SSQ, neither before or after $\mathrm{VR}$ exposure $(\mathrm{M}=0.05, \mathrm{SD}=0.04$, Range: $0-0.09)$. Moreover, the $\mathrm{BF}_{10}\left(\mathrm{BF}_{10}=\right.$ 
$169,95 \% \mathrm{Cl}$ Post-Pre $=[-0.17,-0.05])$ indicated that the average rating of discomforts on the SSQ was lower after VR exposure compared to before $(M=0.30, S D=0.30$, Range: $0-0.75)$ (Figure 8B). In addition, the drop in SSQ ratings was consistent across each SSQ item (Figure 8C).
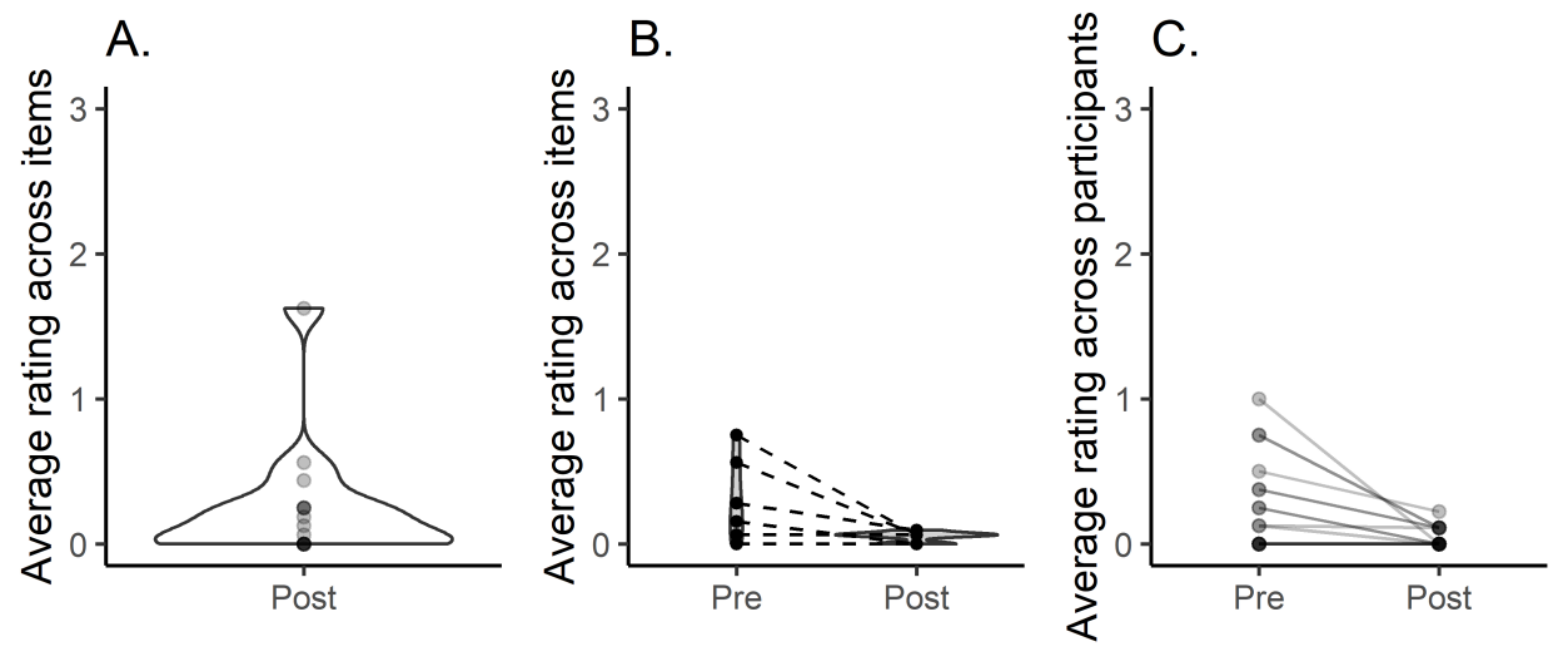

Figure 8. Cybersickness ratings. Post-VR SSQ ratings of healthy participants (A), pre-post VR SSQ ratings of 6 stroke patients (B). One stroke patient only completed the SSQ after the VR exposure. Pre-post VR SSQ ratings averaged across patients for each individual SSQ item (C). There are 16 SSQ items, but some of the data points overlap.

\subsection{USER EVALUATIONS}

A total of 15 healthy controls and 3 stroke patients evaluated different aspects of the game. The healthy controls rated the usability of the user interface $(M=4.3, S D=0.5$, Range: $3-5)$ and the touch controllers ( $M=3.7, S D=1$, Range: $2-5$ ) of our first game prototype on average in a positive way (i.e. >3) (Figure 9A, Figure 9B). However, the stroke patients experienced issues with the touch controller and gave a neutral rating regarding the usability of the touch controllers ( $M=3.3, S D=1$, Range: 2-5). P1 had a tendency to clinch the hand rather than pressing a single button. For this reason, we added an elaborate practice to learn to push the buttons of the controller separately to our game. Moreover, some patients pressed the Oculus Home Button, which made them accidentally leave the game. For this reason, a 3D printed cap blocking the functionality of this button was added. In addition to some usability issues, healthy controls ( $M=2.8, S D=0.7$, Range: $2-4$ ) and stroke patients ( $M=3.1, S D=1.1$, Range: 1-4.5) gave neutral ratings on average regarding sense of presence (Figure 9C). Healthy controls and stroke patients on average did report feeling motivated (healthy controls: $M=3.7, S D=$ 0.7, Range: 1.7-4.4; stroke patients: $M=3.7, S D=0.3$, Range: 3.1-4.1) (Figure 9D). Moreover, healthy controls rated the game narrative in a negative way $(M=2.5, S D=1.1$, Range: $1-4)$, but the stroke patients rated the narrative neutral to positive ( $M=3.6, S D=0.7$, Range: 2.8-4.4) (Figure 9E). Additionally, the 4 stroke patients who played the game for 6 sessions were asked whether they enjoyed the game and experienced any physical discomforts at the end of each session. No physical 
discomforts were reported. The rating of the user experience was consistently positive $(M=4.9, S D=$ 0.3, Range: 4-5) across sessions.

A.

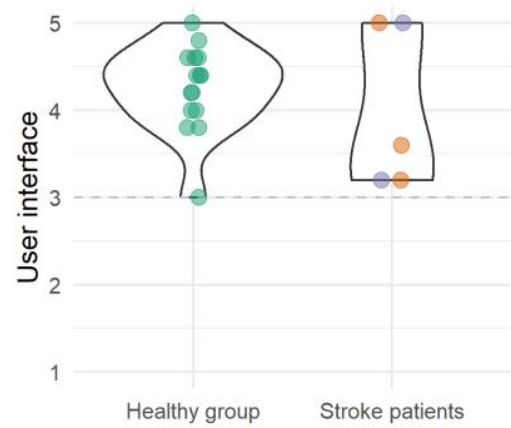

D.

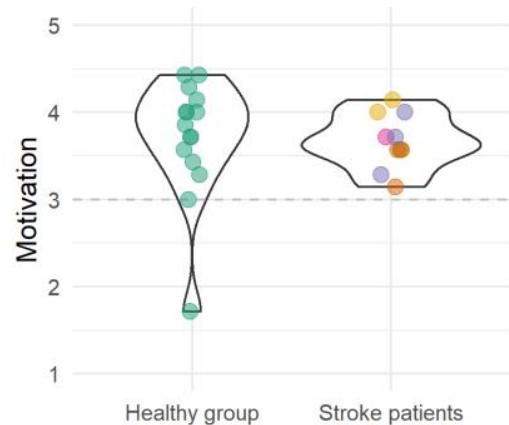

B.

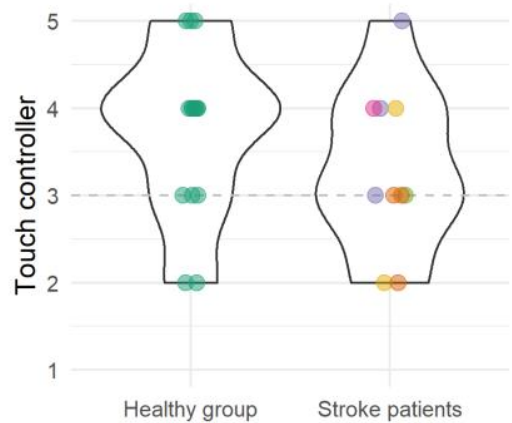

E.

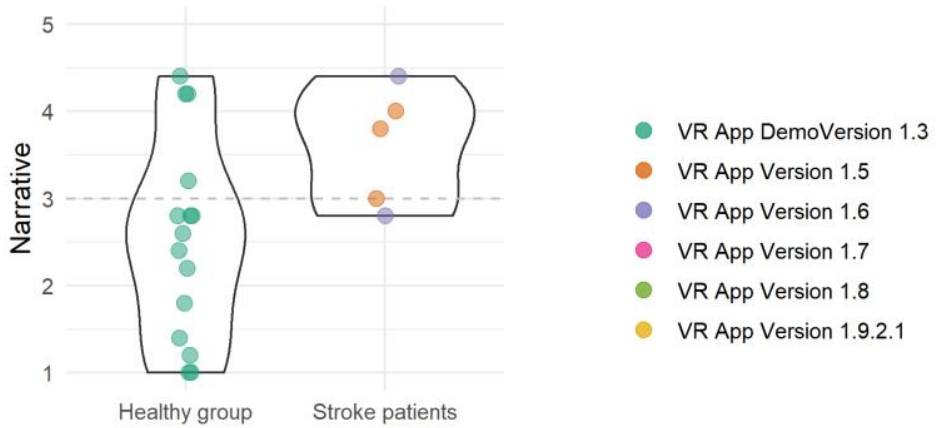

C.

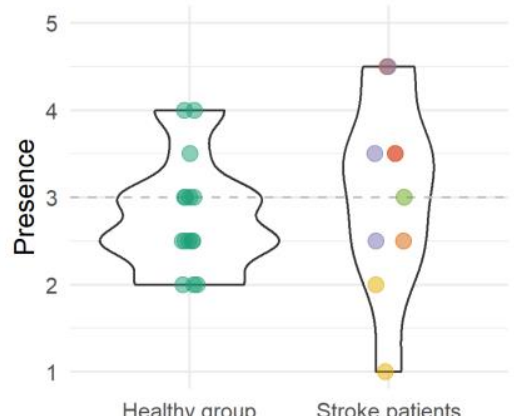

Figure 9. User evaluations across multiple versions of the game of healthy participants and stroke patients. Note that there are not always 7 data points for the stroke group, because patients $\mathrm{P} 2$ and $\mathrm{P} 3$ evaluated two versions of the game (v1.5 and v1.6) and patient P7 evaluated game version 1.9.2.1 in two subsequent game sessions.

\subsection{GAME DATA}

\subsubsection{Correspondence of spatial attention impairment between computer and VR tasks}

There was a significant two-way interaction between visual field and task for patient P4 (Figure 10A, Table 4). That is, the performance difference between the left and right visual field was more pronounced in the non-VR cancellation task compared to the VR rehabilitation task with the nonmoving cues and targets $(95 \% \mathrm{Cl}=[0.07,0.40])$ and there was no significant difference compared to the VR rehabilitation task with the moving cues and targets $(95 \% \mathrm{Cl}=[-0.06,0.19])$. In each of these three tasks there was a significant difference in performance between the left and right visual field (non-VR: 95\% Cl [-0.74, -0.62], VR moving cue/target: 95\% Cl [-0.72, -0.50], VR non-moving cue/target: $95 \% \mathrm{Cl}[-0.59,-0.29])$. For patient $\mathrm{P} 6$, there was no interaction between the task and visual field. Performance was worse in the left than right visual field in the non-VR cancellation task $(95 \% \mathrm{Cl}[-0.23$, $-0.08])$, in the VR task with the non-moving cue/target (95\% $\mathrm{Cl}[-0.33,-0.14])$, and in the VR task with moving cue/target $(95 \% \mathrm{Cl}[-0.22,-0.00])$. For patient $\mathrm{P} 7$, there was no significant interaction between 
the visual field and task, neither a main effect of task nor a main effect of visual field. P5 performed close to ceiling in all conditions ( $M=.99, S D=0.01$, Range: $0.98-1$ ).

\subsubsection{Effect of cue and target location on performance}

For P4, there was a significant three-way interaction of the cue, visual field and type of VR task (Figure 10B, Table 4). The effect of the cue on performance differed significantly between the two VR tasks in the right visual field $(95 \% \mathrm{Cl}=[0.08,0.38])$, but not in the left visual field $(95 \% \mathrm{Cl}=[-0.12,0.29])$. That is, in the right visual field, performance was better with the cue than without the cue in the task with the non-moving cue/target $(95 \% \mathrm{Cl}=[0.05,0.23])$. There was no significant difference in performance with versus without cue in the task with the moving cue/target $(95 \% \mathrm{Cl}=[-0.22,0.03])$. In the left visual field, performance was better with cue versus without the cue in the task with the non-moving cue/target $(95 \% \mathrm{Cl}=[0.04,0.36])$. There was no significant difference in performance with versus without the cue in the task with the moving cue/target $(95 \% \mathrm{Cl}=[-0.01,0.23])$.

For P6, there was no significant three-way interaction of the cue, visual field and type of VR task. There was a significant two-way interaction of the cue and VR task. That is, in the right visual field, performance was better with versus without cue in the VR task with the non-moving cue/target (95\% $\mathrm{Cl}=[0.19,0.39])$, while there was no significant difference with versus without cue in the VR task with the moving cue/target $(95 \% \mathrm{Cl}=[-0.05,0.15])$. In the left visual field, performance was better with versus without cue in the $V R$ task with the non-moving cue/target $(95 \% \mathrm{Cl}=[0.30,0.44])$, while there was no significant difference with versus without cue in the VR task with the moving cue/target (95\% $\mathrm{Cl}=[-0.09,0.12])$.

For P7, there was no significant three-way interaction, nor a significant two-way interaction, nor a main effect of visual field, cue or task on performance. P5 always performed close to ceiling $(M=1$, $\mathrm{SD}=0.01$, Range: 0.99-1). 
A.

P4

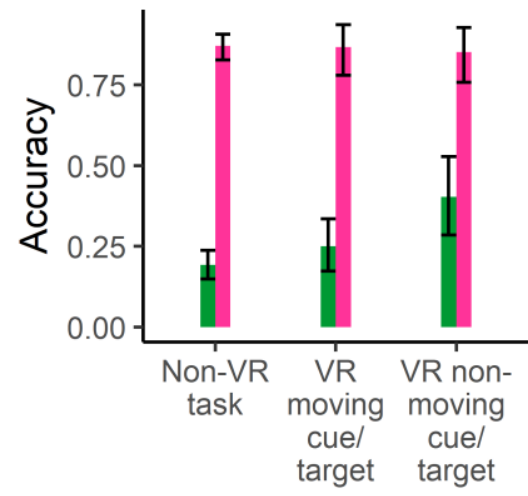

P6

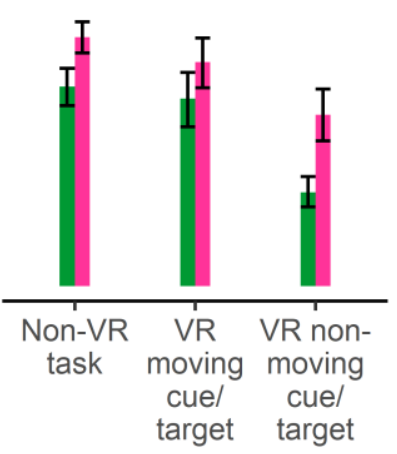

P7

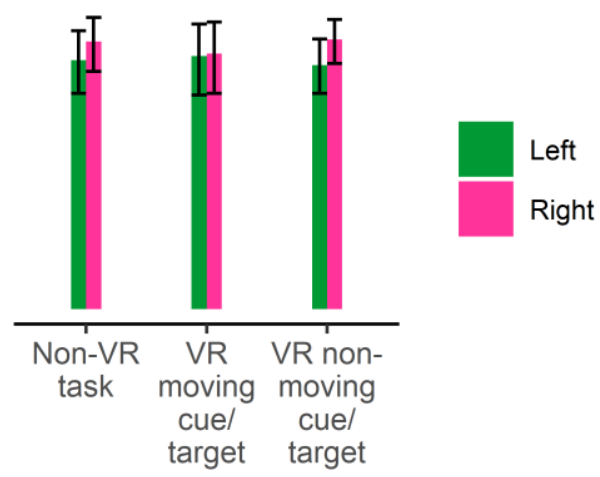

B.

P4

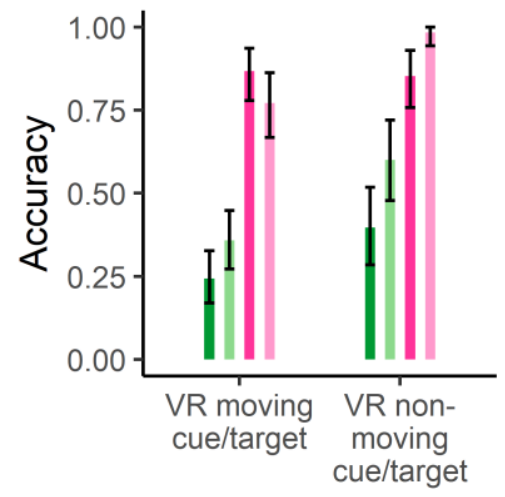

P6

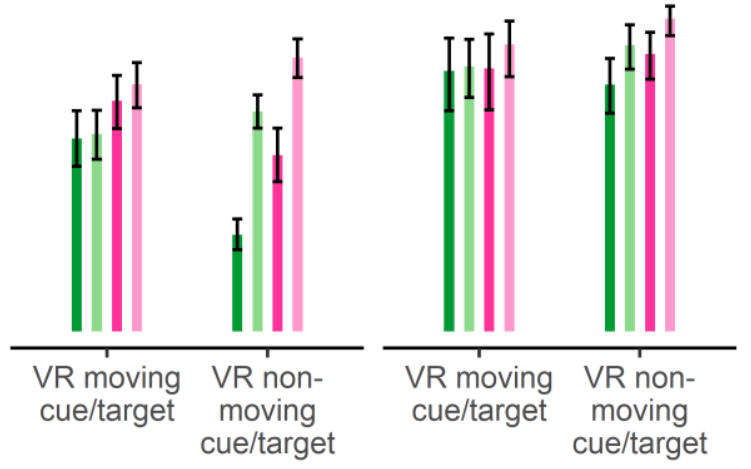

No cue Left

Cue Left No cue Right

Cue Right

Figure 10. Performance as a function of the type of task (i.e., non-VR cancellation task, VR moving cue/target, VR non-moving cue/target) and visual field (A). Performance as a function of type of VR task (i.e. VR moving cue/target, VR non-moving cue/target), visual field and presence or absence of cue (B). Data are shown for each individual patient. Bars represent observed accuracy, error bars represent the $95 \%$ credible intervals of accuracy. Data of P5 is not shown as he performed close to ceiling in all conditions. 


\begin{tabular}{|c|c|c|c|c|c|c|c|c|c|}
\hline \multicolumn{10}{|c|}{ Correspondence of spatial attention impairment between computer and VR tasks } \\
\hline \multirow{3}{*}{$\begin{array}{l}\text { Predictor } \\
\text { Intercept }\end{array}$} & \multicolumn{3}{|c|}{ P4 } & \multicolumn{3}{|c|}{ P6 } & \multicolumn{3}{|c|}{ P7 } \\
\hline & \multirow{2}{*}{$\begin{array}{c}\mathbf{E} \\
-1.44\end{array}$} & \multicolumn{2}{|c|}{$95 \% \mathrm{Cl}$} & \multirow{2}{*}{$\begin{array}{c}\mathbf{E} \\
0.48\end{array}$} & \multicolumn{2}{|c|}{$95 \% \mathrm{Cl}$} & \multirow{2}{*}{$\begin{array}{c}\mathbf{E} \\
1.24\end{array}$} & \multicolumn{2}{|c|}{$95 \% \mathrm{Cl}$} \\
\hline & & -1.74 & -1.16 & & 0.24 & 0.73 & & 0.70 & 1.84 \\
\hline Right & 3.36 & 2.91 & 3.83 & 0.74 & 0.37 & 1.13 & 0.36 & -0.45 & 1.20 \\
\hline VR Moving cue/target & 0.33 & -0.20 & 0.87 & -0.16 & -0.58 & 0.26 & 0.08 & -0.78 & 0.96 \\
\hline $\begin{array}{l}\text { VR non-moving } \\
\text { cue/target }\end{array}$ & 1.04 & 0.44 & 1.65 & -1.38 & -1.72 & -1.05 & -0.10 & -0.84 & 0.60 \\
\hline $\begin{array}{l}\text { Right * VR Moving } \\
\text { cue/target }\end{array}$ & -0.32 & -1.24 & 0.67 & -0.24 & -0.86 & 0.39 & -0.31 & -1.55 & 0.94 \\
\hline $\begin{array}{l}\text { Right * VR non-moving } \\
\text { cue/target }\end{array}$ & -1.17 & -2.18 & -0.16 & 0.28 & -0.27 & 0.83 & 0.13 & -0.98 & 1.18 \\
\hline \multicolumn{10}{|c|}{ Effect of cue and target location on performance } \\
\hline & \multicolumn{3}{|c|}{ P4 } & \multicolumn{3}{|c|}{ P6 } & \multicolumn{3}{|c|}{ P7 } \\
\hline Predictor & $\mathbf{E}$ & \multicolumn{2}{|c|}{$95 \% \mathrm{Cl}$} & $\mathbf{E}$ & \multicolumn{2}{|c|}{$95 \% \mathrm{Cl}$} & $\mathbf{E}$ & \multicolumn{2}{|c|}{$95 \% \mathrm{Cl}$} \\
\hline Intercept & -0.59 & -0.98 & -0.21 & 0.39 & 0.09 & 0.71 & 1.39 & 0.87 & 1.94 \\
\hline Right & 1.83 & 1.18 & 2.53 & 0.68 & 0.23 & 1.15 & 0.50 & -0.38 & 1.45 \\
\hline No cue & -0.56 & -1.13 & 0.02 & -0.06 & -0.52 & 0.38 & -0.06 & -0.93 & 0.81 \\
\hline $\begin{array}{l}\text { VR non-moving } \\
\text { cue/target }\end{array}$ & 1.01 & 0.39 & 1.67 & 0.29 & -0.09 & 0.67 & 0.46 & -0.33 & 1.24 \\
\hline Right $*$ No cue & 1.24 & 0.17 & 2.32 & -0.19 & -0.87 & 0.48 & -0.46 & -1.78 & 0.83 \\
\hline $\begin{array}{l}\text { Right } * \text { VR non-moving } \\
\text { cue/target }\end{array}$ & 2.38 & 0.28 & 5.49 & 0.20 & -0.45 & 0.83 & 0.51 & -0.86 & 1.86 \\
\hline $\begin{array}{l}\text { No cue * VR non-moving } \\
\text { cue/target }\end{array}$ & -0.29 & -1.19 & 0.61 & -1.51 & -2.06 & -0.97 & -0.71 & -1.85 & 0.42 \\
\hline $\begin{array}{l}\text { Right } * \text { No cue } * \text { VR non- } \\
\text { moving cue/target }\end{array}$ & -3.23 & -6.65 & -0.82 & 0.31 & -0.58 & 1.25 & 0.02 & -1.81 & 1.77 \\
\hline
\end{tabular}

Note. Detection probabilities were modelled using a Bayesian logistic regression model, estimated with the brms package in $\mathrm{R}$ (Bürkner, 2017). Estimates are presented in log odds. $\mathrm{E}=$ point estimate, $95 \% \mathrm{Cl}=95 \%$ credible interval.

\subsubsection{Patient-tailored design}

There was a significant interaction between the patient-tailored algorithm and whether the patient had neglect or not. That is, the target locations were significantly more biased towards the left visual field for the neglect patients compared to the patients without neglect for the algorithm based on the logistic model versus the algorithm based on the $\operatorname{CoC}(95 \% \mathrm{Cl}=[0.56,4.81]$, Figure $11 \mathrm{~A}$, Table 5). For both algorithms, the target locations were more biased towards the left visual field for the neglect than the control case (CoC: $95 \% \mathrm{Cl}=[-4.53,-1.39]$; Logistic model: $95 \% \mathrm{Cl}[-6.99,-4.27])$. These results were also confirmed by a simulation. That is, target locations were more biased towards the left visual field for simulated neglect cases for the algorithm based on the logistic model than for the algorithm based on the CoC (Figure 11B). 
A.

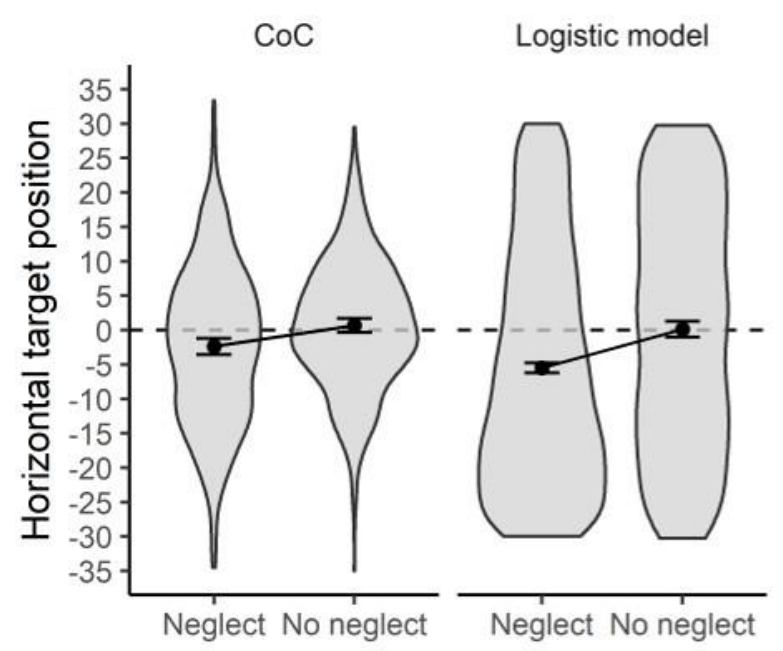

B.

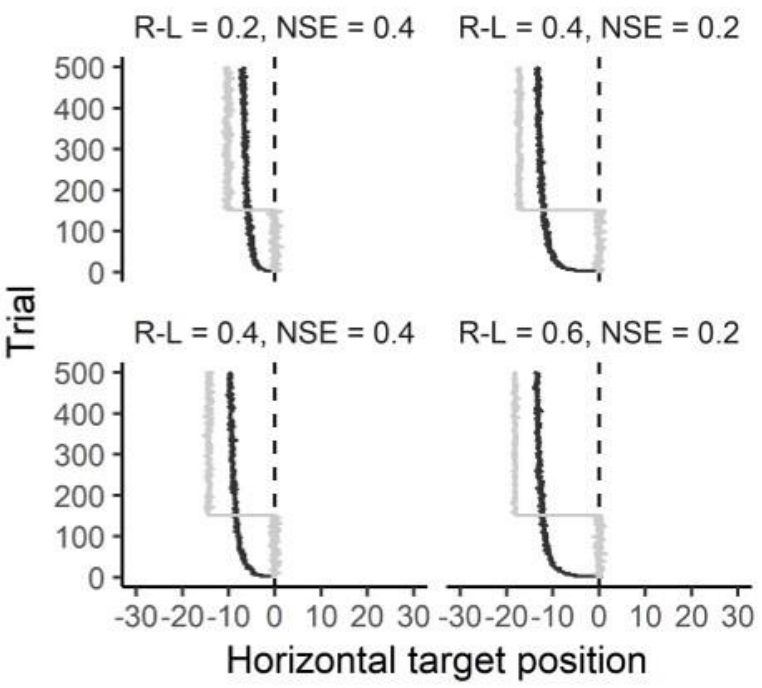

- $\mathrm{CoC}$ - Logistic model

Figure 11. Distribution of target locations split up for the patient-tailored algorithm that was used and whether the patient had neglect or not $(A)$ and the expected horizontal target positions of 500 trials for 4 different simulated patient cases (B). R-L = difference in probability to detect targets between the right and left visual field, NSE = probability to miss targets on the right visual field, representing non-spatial errors.

Table 5. Results of patient-tailored design comparison.

\begin{tabular}{lccc}
\multicolumn{1}{c}{ Predictor } & Estimate & & $\mathbf{9 5 \%} \mathbf{C l}$ \\
\hline Intercept & -2.36 & -3.58 & -1.19 \\
\hline Logistic model & -3.15 & -4.55 & -1.68 \\
\hline No neglect & 3.00 & 1.39 & 4.53 \\
\hline Logistic model * No neglect & 2.65 & 0.56 & 4.81 \\
\hline
\end{tabular}

Note. Detection probabilities were modelled using a Bayesian logistic regression model, estimated with the brms package in $\mathrm{R}$ (Bürkner, 2017). $\mathrm{E}=$ point estimate, $95 \% \mathrm{Cl}=95 \%$ credible interval.

\section{DISCUSSION}

We iteratively designed an immersive VR rehabilitation game for neglect patients combining multiple intervention principles and pilot-tested our game in small samples of healthy controls and stroke patients.

\subsection{THE IMMERSIVE VR REHABILITATION GAME DID NOT INDUCE CYBERSICKNESS}

We found no signs of severe or moderate cybersickness, neither in healthy controls nor in stroke patients. Stroke patients even reported less cybersickness symptoms after playing the game compared to before. There may be multiple reasons for this trend. One possibility is that the anticipation of using new technology introduced some physical discomfort before the VR exposure which then dissipated after the exposure. An alternative explanation is that patients engaged their attention with the sensory stimulation in the VR environment and payed less attention to internal body signals. Indeed, many researchers are exploring the potential of VR to distract patients from painful experiences (Keefe 
et al., 2012). Thus, in contrast to the concern that immersive VR may introduce cybersickness in patients, our results suggest instead that immersive VR may have a positive effect on physical comfort in stroke patients. Whether this trend towards less cybersickness after using immersive VR would remain present in a larger and more representative sample of stroke patients requires further examination. Moreover, our results clarify the importance of obtaining a baseline-measurement of cybersickness symptoms.

\subsection{USER EXPERIENCE WAS NEUTRAL TO POSITIVE}

Ratings of the user experience were generally neutral to positive. The four stroke patients who played the game for 6 sessions rated the game consistently positively across the sessions. These results suggest that our immersive VR game can keep patients motivated across many sessions. However, our measurement of user experience for each game session was limited to a simple question: "did you like the game today?", as game sessions needed to be short to fit into patient's treatment schedules. We cannot exclude that a more extensive user experience questionnaire at the end of each game session would have led to a more nuanced result. Furthermore, our results regarding user experience must be further evaluated in a larger and systematically recruited stroke sample.

\subsection{IMMERSIVE VR GAMES MUST BE DESIGNED SPECIFICALLY FOR THE STROKE POPULATION}

Observations of usability issues in Phase 1 and Phase 2 clarified that the user interface and use of the touch controllers needed to be designed specifically for stroke patients. It was apparent that patients needed practice before being able to use the controllers independently. We also had to make several adjustments to the touch controller such as adding a 3D printed cap and stickers. In Phase 3, we observed considerably less usability issues, suggesting that the iterative design helped mitigate usability issues. Our results may be interpreted as a sign that more intuitive interaction devices, such as motion-capture wearable devices or cameras may improve usability of IVR systems. Indeed, other researchers have advised to avoid using handheld controllers when working with the stroke population (Alankus et al., 2010). However, gesture-based interaction methods are not necessarily more intuitive or easier to use and problems of cultural differences in the meaning of different gestures can also introduce difficulties in designing intuitive easy-to-use interactions suitable for different cultures (Norman, 2010). Moreover, handheld controllers are the default interaction devices of recent commercially available HMDs. Thus, using the default commercially available hardware without excessive customization, may make IVR systems more feasible to adopt and use in clinical practice.

Another aspect that may need to be designed specifically for the patient population is the game narrative. Interestingly, it seemed that stroke patients rated the game narrative more positively 
compared to the healthy control group. This may relate to the fact that the healthy group was on average younger compared to the stroke patients and we designed the narrative specifically for older adults. However, given the small sample size in the current study, further research is required to establish whether there is indeed a reliable relation between how game narratives are experienced by stroke patients and how this may be related to age.

\subsection{PRELIMINARY ASSESSMENT OF GAME MECHANICS}

Last, we assessed the most important game mechanics in 4 stroke patients who played the game for multiple sessions.

\subsubsection{Spatial attention impairments in VR corresponded to a non-VR cancellation task}

Spatial impairments measured with a non-VR cancellation task corresponded with spatial impairments measured with our VR task, irrespective of the exact game version that was used. Thus, it is feasible to detect hemispatial neglect with our VR game. To know to what extent our game versions would differ from each other in their ability to detect hemispatial neglect, a larger stroke sample would need to be recruited that plays the different game versions for several sessions. Moreover, in the future, it would be interesting to explore to what extent a more adaptive game would result in a more sensitive assessment (and potentially more effective rehabilitation) of hemispatial neglect. That is, rather than being fixed, one could automatically adapt the duration, size or other features of the target and cues to the performance of individual patients. This individualization may maximize the efficacy of the VR game for rehabilitating hemispatial neglect, as the game would match better with the individual patient's abilities. Indeed, some studies suggest that adaptive training can be more effective in improving cognitive functions or attaining learning goals than non-adaptive training in various populations (Pedullà et al., 2016; Plass et al., 2019; Sampayo-Vargas et al., 2013; although see Vanbecelaere et al., 2020). However, increased adaptivity comes at a cost. Automatically optimizing many game features to individual patients requires a large amount of data as one needs to estimate the effect of changing each of the game features on patients performance. If game features are adjusted based on too little data, the adaptivity can fail to adequately adjust to the individual patient, potentially leading to an overly difficult or overly simple game. For this reason, we now chose to make certain game features non-adaptive.

\subsubsection{Predictive multisensory looming cues improved target detection}

Our rehabilitation game aims to promote spatial attention orientation towards the neglected visual field using a predictive multisensory looming cue. To evaluate whether our game succeeded in achieving this goal, we tested the effect of the cue on performance in four stroke patients. The cue in our VR game resulted in better performance and, more importantly, increased target detection in the 
left visual field. Thus, patients were able to use the cue to detect more targets. However, we also found that the cueing effect on performance was weaker in the game scenes in which the cue and target moved. The moving cues and targets were only presented in the forest scenes. Thus, it is unclear whether the cueing effect was reduced due to the scene itself or due to the fact that the cue and/or target moved.

\subsubsection{Successful patient-tailored presentation of sensory stimulation in the neglected visual field}

Our rehabilitation game aims to present sensory stimulation in the neglected visual field in a patienttailored way. To evaluate whether the game algorithms successfully presented sensory stimulation in the patient's neglected visual field, we tested whether the target locations in our VR game were biased towards the contralesional side of space in patients with significant spatial attention impairments. Our results confirmed that indeed the target locations were biased towards the neglected visual field and that this was more pronounced using an algorithm based on a logistic model than an algorithm based on the average location of missed targets. This finding was further confirmed in a simulation.

However, although our rehabilitation game aims to present sensory stimulation in the neglected visual field, it is unclear what the neglected side of space exactly is. That is, some researchers have proposed that the orientation of the trunk determines what constitutes the neglected versus non-neglected side of space (Karnath et al., 1991). Evidence for this idea came from 4 neglect patients who had faster response times to targets presented in the left visual field when the trunk was rotated towards the left side so that the targets in the left visual field were actually located to the right side of the trunk midline (Karnath et al., 1991). One problem with these findings was that the opposite result was not found. That is, if the trunk midline would be the sole determinant of neglected space, then there should be worse performance for right visual field stimuli located to the left of the trunk midline. The neglect patients in Karnath's study did not show this expected increase in response times for right visual field targets when the trunk was rotated towards the right side. Moreover, it has also been reported that neglect patients showed reading impairments for stimuli in the left visual field with the body rotated so that the left visual field stimuli were located on the right side of the body (Hillis et al., 1998). The latter suggests that the visual field position of the stimuli is also important. Moreover, given the heterogeneity and size of brain lesions of neglect patients, it is more likely that the position of the eyes, head and body all influence the spatial reference frame (Corbetta \& Shulman, 2011).

\subsection{CONCLUSIONS}

To conclude, we have presented the rationale and pilot results of a new immersive virtual reality neglect rehabilitation game. We showed that self-reported cybersickness complaints decreased after VR exposure in 6 stroke patients. Moreover, our pilot results suggest that immersive virtual reality 
gaming can be experienced in a positive way by stroke patients, even after playing the game for 6 sessions. We also assessed the most important game mechanics, showing that neglect symptoms corresponded between our VR game and a computerized cancellation task and that we were successful at tailoring the game to neglect symptoms of individual patients. These data suggest that our immersive VR game is feasible, and promising, to use in stroke patients.

\section{FUNDING}

This work was funded by a research grant of the Flemish Fund for Scientific Research (FWO) awarded to H.H. (1171717N, 1171719N), R.v.E. and V.V.A. (G078915N) and C.R.G. (G072517N).

\section{Disclosure StATEMENT}

The authors declare no conflict of interest. 


\section{REFERENCES}

Alankus, G., Lazar, A., May, M., \& Kelleher, C. (2010). Towards customizable games for stroke rehabilitation. Proceedings of the SIGCHI Conference on Human Factors in Computing Systems, 2113-2122. https://doi.org/10.1145/1753326.1753649

Ansuini, C., Pierno, A. C., Lusher, D., \& Castiello, U. (2006). Virtual reality applications for the remapping of space in neglect patients. Restorative Neurology and Neuroscience, 24(4-6), 431-441.

Aravind, G., \& Lamontagne, A. (2014). Perceptual and locomotor factors affect obstacle avoidance in persons with visuospatial neglect. Journal of NeuroEngineering and Rehabilitation, 11(38), 110. https://doi.org/10.1186/1743-0003-11-38

Bailey, M. J., Riddoch, M. J., \& Crome, P. (2004). Test-retest stability of three tests for unilateral visual neglect in patients with stroke: Star Cancellation, Line Bisection, and the Baking Tray Task. Neuropsychological Rehabilitation, 14(4), 403-419. https://doi.org/10.1080/09602010343000282

Bartolomeo, P., Siéroff, E., Decaix, C., \& Chokron, S. (2001). Modulating the attentional bias in unilateral neglect: The effects of the strategic set. Experimental Brain Research, 137(3-4), 432-444. https://doi.org/10.1007/s002210000642

Bowen, A., Hazelton, C., Pollock, A., \& Lincoln, N. B. (2013). Cognitive rehabilitation for spatial neglect following stroke. In The Cochrane Collaboration (Ed.), Cochrane Database of Systematic Reviews. John Wiley \& Sons, Ltd. http://doi.wiley.com/10.1002/14651858.CD003586.pub3

Bowen, A., McKenna, K., \& Tallis, R. C. (1999). Reasons for Variability in the Reported Rate of Occurrence of Unilateral Spatial Neglect After Stroke. Stroke, 30(6), 1196-1202. https://doi.org/10.1161/01.STR.30.6.1196 
Immersive VR Neglect Rehabilitation

Bruun-Pedersen, J. R., Serafin, S., \& Kofoed, L. B. (2016). Restorative Virtual Environment Design for Augmenting Nursing Home Rehabilitation. https://doi.org/10.4101/jvwr.v9i3.7224

Burke, J. W., McNeill, M. D. J., Charles, D. K., Morrow, P. J., Crosbie, J. H., \& McDonough, S. M. (2009). Optimising Engagement for Stroke Rehabilitation Using Serious Games. Vis. Comput., 25(12), 1085-1099. https://doi.org/10.1007/s00371-009-0387-4

Bürkner, P.-C. (2017). brms: An R Package for Bayesian Multilevel Models Using Stan. Journal of Statistical Software, 80(1), 1-28. https://doi.org/10.18637/jss.v080.i01

Busselle, R., \& Bilandzic, H. (2009). Measuring Narrative Engagement. Media Psychology, 12(4), 321347. https://doi.org/10.1080/15213260903287259

Castiello, U., Lusher, D., Burton, C., Glover, S., \& Disler, P. (2004). Improving left hemispatial neglect using virtual reality. Neurology, 62(11), 1958-1962. https://doi.org/10.1212/01.WNL.0000128183.63917.02

Cermak, S., \& Hausser, J. (1989). The Behavioral Inattention Test for Unilateral Visual Neglect (Vol. 7). https://doi.org/10.1300/J148v07n03_04

Chatterjee, A., Thompson, K. A., \& Ricci, R. (1999). Quantitative Analysis of Cancellation Tasks in Neglect. Cortex, 35(2), 253-262. https://doi.org/10.1016/S0010-9452(08)70798-6

Chen, P., Pitteri, M., Gillen, G., \& Ayyala, H. (2018). Ask the experts how to treat individuals with spatial neglect: A survey study. Disability and Rehabilitation, 40(22), 2677-2691. https://doi.org/10.1080/09638288.2017.1347720

Corbetta, M., \& Shulman, G. L. (2011). Spatial neglect and attention networks. Annual Review of Neuroscience, 34, 569-599. https://doi.org/10.1146/annurev-neuro-061010-113731

de Haan, B., Clas, P., Juenger, H., Wilke, M., \& Karnath, H.-O. (2015). Fast semi-automated lesion demarcation in stroke. Neurolmage: Clinical, 9, 69-74. https://doi.org/10.1016/j.nicl.2015.06.013 
De Schutter, B., \& Vanden Abeele, V. (2008, January). Meaningful Play in Elderly Life. Annual Meeting of the International Communication Association. Annual Meeting of the International Communication Association, Montreal, Quebec, Canada. http://limo.libis.be/primoexplore/fulldisplay/LIRIAS1674322/Lirias

DeGutis, J. M., \& Van Vleet, T. (2010). Tonic and Phasic Alertness Training: A Novel Behavioral Therapy to Improve Spatial and Non-Spatial Attention in Patients with Hemispatial Neglect. Frontiers in Human Neuroscience, 4. https://doi.org/10.3389/fnhum.2010.00060

Dent, K., \& Humphreys, G. W. (2011). Neuropsychological evidence for a competitive bias against

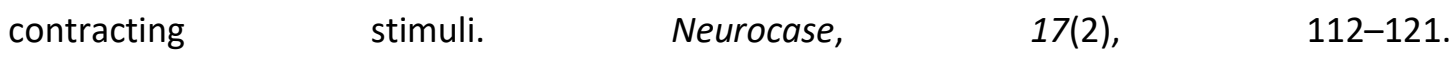
https://doi.org/10.1080/13554794.2010.498381

Ducheneaut, N., Yee, N., Nickell, E., \& Moore, R. J. (2006). “Alone together?": Exploring the social dynamics of massively multiplayer online games. Proceedings of the SIGCHI Conference on Human Factors in Computing Systems, 407-416. https://doi.org/10.1145/1124772.1124834

Einhäuser, W., Moeller, G. U., Schumann, F., Conradt, J., Vockeroth, J., Bartl, K., Schneider, E., \& König, P. (2009). Eye-Head Coordination during Free Exploration in Human and Cat. Annals of the New York Academy of Sciences, 1164(1), 353-366. https://doi.org/10.1111/j.1749$6632.2008 .03709 . x$

Ekman, U., Fordell, H., Eriksson, J., Lenfeldt, N., Wåhlin, A., Eklund, A., \& Malm, J. (2018). Increase of frontal neuronal activity in chronic neglect after training in virtual reality. Acta Neurologica Scandinavica, 138(4), 284-292. https://doi.org/10.1111/ane.12955

Fasotti, L., \& van Kessel, M. (2013). Novel Insights in the Rehabilitation of Neglect. Frontiers in Human Neuroscience, 7. https://doi.org/10.3389/fnhum.2013.00780 
Foerster, R. M., Poth, C. H., Behler, C., Botsch, M., \& Schneider, W. X. (2016). Using the virtual reality device Oculus Rift for neuropsychological assessment of visual processing capabilities. Scientific Reports, 6(37016), 1-10. https://doi.org/10.1038/srep37016

Fordell, H., Bodin, K., Eklund, A., \& Malm, J. (2016). RehAtt - scanning training for neglect enhanced by multi-sensory stimulation in Virtual Reality. Topics in Stroke Rehabilitation, 23(3), 191-199. https://doi.org/10.1080/10749357.2016.1138670

Frassinetti, F., Pavani, F., \& Làdavas, E. (2002). Acoustical Vision of Neglected Stimuli: Interaction among Spatially Converging Audiovisual Inputs in Neglect Patients. Journal of Cognitive Neuroscience, 14(1), 62-69. https://doi.org/10.1162/089892902317205320

Fruhmann-Berger, M., \& Karnath, H.-O. (2005). Spontaneous eye and head position in patients with spatial neglect. Journal of Neurology, 252(10), 1194-1200. https://doi.org/10.1007/s00415005-0831-y

Geng, J. J., \& Behrmann, M. (2006). Competition between simultaneous stimuli modulated by location probability in hemispatial neglect. Neuropsychologia, 44(7), 1050-1060. https://doi.org/10.1016/j.neuropsychologia.2005.10.026

Gould, J. D., \& Lewis, C. (1985). Designing for usability: Key principles and what designers think. Communications of the ACM, 28(3), 300-311. https://doi.org/10.1145/3166.3170

Guitton, D., \& Volle, M. (1987). Gaze control in humans: Eye-head coordination during orienting movements to targets within and beyond the oculomotor range. Journal of Neurophysiology, 58(3), 427-459. https://doi.org/10.1152/jn.1987.58.3.427

Heilman, K. M., Bowers, D., Valenstein, E., \& Watson, R. T. (1987). Hemispace and hemispatial neglect. In Advances in Psychology (Vol. 45, pp. 115-150). Elsevier Science. http://dx.doi.org/10.1016/S0166-4115(08)61711-2 
Immersive VR Neglect Rehabilitation

Hillis, A. E., Rapp, B., Benzing, L., \& Caramazza, A. (1998). Dissociable Coordinate Frames of Unilateral Spatial Neglect: "Viewer-Centered" Neglect. Brain and Cognition, 37(3), 491-526. https://doi.org/10.1006/brcg.1998.1010

Husain, M., \& Rorden, C. (2003). Non-spatially lateralized mechanisms in hemispatial neglect. Nature Reviews Neuroscience, 4(1), 26-36. https://doi.org/10.1038/nrn1005

Huygelier, H., \& Gillebert, C. R. (2020). Quantifying egocentric spatial neglect with cancellation tasks: A theoretical validation. Journal of Neuropsychology, 14(1), 1-19. https://doi.org/10.1111/jnp.12177

Huygelier, H., Gillebert, C. R., van Ee, R., \& Vanden Abeele, V. (2017). The Design of a Virtual Reality Game for Stroke-Induced Attention Deficits. Extended Abstracts Publication of the Annual Symposium on Computer-Human Interaction in Play, 223-230. https://doi.org/10.1145/3130859.3131308

Huygelier, H., Moore, M. J., Demeyere, N., \& Gillebert, C. R. (2020). Non-spatial impairments affect false positive neglect diagnosis based on cancellation tasks. Journal of the International Neuropsychological Society, 1-11. https://doi.org/10.1017/S1355617720000041

Huygelier, H., Schraepen, B., Demeyere, N., \& Gillebert, C. R. (2019). The Dutch version of the Oxford Cognitive Screen (OCS-NL): Normative data and their association with age and socio-economic status. Aging, Neuropsychology, and 1-22. https://doi.org/10.1080/13825585.2019.1680598

Karnath, H. O., Schenkel, P., \& Fischer, B. (1991). Trunk orientation as the determining factor of the "contralateral" deficit in the neglect syndrome and as the physical anchor of the internal representation of body orientation in space. Brain: A Journal of Neurology, 114 ( Pt 4), 19972014. 
Katz, N., Ring, H., Naveh, Y., Kizony, R., Feintuch, U., \& Weiss, P. L. (2005). Interactive virtual environment training for safe street crossing of right hemisphere stroke patients with unilateral spatial neglect. Disability and Rehabilitation, 27(20), 1235-1244.

Keefe, F. J., Huling, D. A., Coggins, M. J., Keefe, D. F., Rosenthal, M. Z., Herr, N. R., \& Hoffman, H. G. (2012). Virtual Reality for Persistent Pain: A New Direction for Behavioral Pain Management. Pain, 153(11), 2163-2166. https://doi.org/10.1016/j.pain.2012.05.030

Kim, J., Kim, K., Kim, D. Y., Chang, W. H., Park, C.-I., Ohn, S. H., Han, K., Ku, J., Nam, S. W., Kim, I. Y., \& Kim, S. I. (2007). Virtual Environment Training System for Rehabilitation of Stroke Patients with Unilateral Neglect: Crossing the Virtual Street. CyberPsychology \& Behavior, 10(1), 7-15. https://doi.org/10.1089/cpb.2006.9998

Lessiter, J., Freeman, J., Keogh, E., \& Davidoff, J. (2001). A Cross-Media Presence Questionnaire: The ITC-Sense of Presence Inventory. Presence: Teleoperators and Virtual Environments, 10(3), 282-297. https://doi.org/10.1162/105474601300343612

Luca, R. D., Buono, V. L., Leo, A., Russo, M., Aragona, B., Leonardi, S., Buda, A., Naro, A., \& Calabrò, R. S. (2019). Use of virtual reality in improving poststroke neglect: Promising neuropsychological and neurophysiological findings from a case study. Applied Neuropsychology: Adult, 26(1), 96100. https://doi.org/10.1080/23279095.2017.1363040

Mainetti, R., Sedda, A., Ronchetti, M., Bottini, G., \& Borghese, N. A. (2013). Duckneglect: Video-games based neglect rehabilitation. Technology and Health Care: Official Journal of the European Society for Engineering and Medicine, 21(2), 97-111. https://doi.org/10.3233/THC-120712

McAuley, E., Duncan, T., \& Tammen, V. V. (1989). Psychometric Properties of the Intrinsic Motivation Inventory in a Competitive Sport Setting: A Confirmatory Factor Analysis. Research Quarterly for Exercise and Sport, 60(1), 48-58. https://doi.org/10.1080/02701367.1989.10607413 
Immersive VR Neglect Rehabilitation

Mirelman, A., Bonato, P., \& Deutsch, J. E. (2009). Effects of Training With a Robot-Virtual Reality System Compared With a Robot Alone on the Gait of Individuals After Stroke. Stroke, 40(1), 169-174. https://doi.org/10.1161/STROKEAHA.108.516328

Moon, H.-S., Shin, S.-W., Chung, S.-T., \& Kim, E. (2019). K-CBS-based unilateral spatial neglect rehabilitation training contents utilizing virtual reality. 2019 International Conference on Electronics, Information, and Communication (ICEIC), 1-3. https://doi.org/10.23919/ELINFOCOM.2019.8706395

Myers, R. L., \& Bierig, T. A. (2000). Virtual Reality and Left Hemineglect: A Technology for Assessment and Therapy. CyberPsychology \& Behavior, 3(3), 465-468. https://doi.org/10.1089/10949310050078922

Nijboer, T. C. W., Kollen, B. J., \& Kwakkel, G. (2014). The Impact of Recovery of Visuo-Spatial Neglect on Motor Recovery of the Upper Paretic Limb after Stroke. PLOS ONE, 9(6), e100584. https://doi.org/10.1371/journal.pone.0100584

Nijboer, T., Van de Port, I., Schepers, V., Post, M., \& Visser-Meily, A. (2013). Predicting functional outcome after stroke: The influence of neglect on basic activities in daily living. Frontiers in Human Neuroscience, 7.

Norman, D. A. (2010). Natural user interfaces are not natural. Interactions, 17(3), 1-5.

Oculus Rift / Oculus. (n.d.). Retrieved February 27, 2020, from https://www.oculus.com/rift/\#oui-cslrift-games=mages-tale

Parker, A., \& Alais, D. (2007). A bias for looming stimuli to predominate in binocular rivalry. Vision Research, 47(20), 2661-2674. https://doi.org/10.1016/j.visres.2007.06.019

Parnandi, A., \& Gutierrez-Osuna, R. (2018). Partial reinforcement in game biofeedback for relaxation training. IEEE Transactions on Affective Computing, 1-1. https://doi.org/10.1109/TAFFC.2018.2842727 
Pedroli, E., Serino, S., Cipresso, P., Pallavicini, F., \& Riva, G. (2015). Assessment and rehabilitation of neglect using virtual reality: A systematic review. Frontiers in Behavioral Neuroscience, 9, 226. https://doi.org/10.3389/fnbeh.2015.00226

Pedullà, L., Brichetto, G., Tacchino, A., Vassallo, C., Zaratin, P., Battaglia, M. A., Bonzano, L., \& Bove, M. (2016). Adaptive vs. non-adaptive cognitive training by means of a personalized App: A randomized trial in people with multiple sclerosis. Journal of NeuroEngineering and Rehabilitation, 13(1), 88. https://doi.org/10.1186/s12984-016-0193-y

Pfeil, K., Taranta, E. M., Kulshreshth, A., Wisniewski, P., \& LaViola, J. J. (2018). A comparison of eyehead coordination between virtual and physical realities. Proceedings of the 15th ACM Symposium on Applied Perception, 1-7. https://doi.org/10.1145/3225153.3225157

Pirovano, M., Surer, E., Mainetti, R., Lanzi, P. L., \& Alberto Borghese, N. (2016). Exergaming and rehabilitation: A methodology for the design of effective and safe therapeutic exergames. Entertainment Computing, 14, 55-65. https://doi.org/10.1016/j.entcom.2015.10.002

Plass, J. L., Homer, B. D., Pawar, S., Brenner, C., \& MacNamara, A. P. (2019). The effect of adaptive difficulty adjustment on the effectiveness of a game to develop executive function skills for learners of different ages. Cognitive Development, 49, 56-67. https://doi.org/10.1016/j.cogdev.2018.11.006

Popović, M. D., Kostić, M. D., Rodić, S. Z., \& Konstantinović, L. M. (2014). Feedback-Mediated Upper Extremities Exercise: Increasing Patient Motivation in Poststroke Rehabilitation. BioMed Research International, 1-11. https://doi.org/10.1155/2014/520374

Richter, G., Raban, D. R., \& Rafaeli, S. (2015). Studying Gamification: The Effect of Rewards and Incentives on Motivation. In T. Reiners \& L. C. Wood (Eds.), Gamification in Education and Business (pp. 21-46). Springer International Publishing. https://doi.org/10.1007/978-3-31910208-5_2 
Immersive VR Neglect Rehabilitation

Rizzo, A. A., Schultheis, M., Kerns, K. A., \& Mateer, C. (2004). Analysis of assets for virtual reality applications in neuropsychology. Neuropsychological Rehabilitation, 14(1-2), 207-239.

Rizzo, A. S., \& Koenig, S. T. (2017). Is clinical virtual reality ready for primetime? Neuropsychology, 31(8), 877-899. https://doi.org/10.1037/neu0000405

Robbins, D. (1971). Partial reinforcement: A selective review of the alleyway literature since 1960. Psychological Bulletin, 76(6), 415-431. http://dx.doi.org/10.1037/h0031890

Robertson, I. H., Mattingley, J. B., Rorden, C., \& Driver, J. (1998). Phasic alerting of neglect patients overcomes their spatial deficit in visual awareness. Nature, 395(6698), 169-172. https://doi.org/10.1038/25993

Rorden, C., Bonilha, L., Fridriksson, J., Bender, B., \& Karnath, H.-O. (2012). Age-specific CT and MRI templates for spatial normalization. Neuroimage, 61(4), 957-965. https://doi.org/10.1016/j.neuroimage.2012.03.020

Rorden, C., \& Karnath, H.-O. (2010). A simple measure of neglect severity. Neuropsychologia, 48(9), 2758-2763. https://doi.org/10.1016/j.neuropsychologia.2010.04.018

Rouder, J. N., Speckman, P. L., Sun, D., Morey, R. D., \& Iverson, G. (2009). Bayesian t tests for accepting and rejecting the null hypothesis. Psychonomic Bulletin \& Review, 16(2), 225-237. https://doi.org/10.3758/PBR.16.2.225

Salazar, A. P. S., Vaz, P. G., Marchese, R. R., Stein, C., Pinto, C., \& Pagnussat, A. S. (2018). Noninvasive Brain Stimulation Improves Hemispatial Neglect After Stroke: A Systematic Review and MetaAnalysis. Archives of Physical Medicine and Rehabilitation, 99(2), 355-366.e1. https://doi.org/10.1016/j.apmr.2017.07.009

Sampayo-Vargas, S., Cope, C. J., He, Z., \& Byrne, G. J. (2013). The effectiveness of adaptive difficulty adjustments on students' motivation and learning in an educational computer game. Computers \& Education, 69, 452-462. https://doi.org/10.1016/j.compedu.2013.07.004 
Sedda, A., Borghese, N. A., Ronchetti, M., Mainetti, R., Pasotti, F., Beretta, G., \& Bottini, G. (2013). Using virtual reality to rehabilitate neglect. Behavioural Neurology, 26(3), 183-185. https://doi.org/10.3233/BEN-2012-129006

Shaqiri, A., \& Anderson, B. (2012). Spatial probability cuing and right hemisphere damage. Brain and Cognition, 80(3), 352-360. https://doi.org/10.1016/j.bandc.2012.08.006

Sturm, W., Thimm, M., Binkofski, F., Horoufchin, H., Fink, G. R., Küst, J., Karbe, H., \& Willmes, K. (2013). Combined Space and Alertness Related Therapy of Visual Hemineglect: Effect of Therapy Frequency. Frontiers in Human Neuroscience, 7. https://doi.org/10.3389/fnhum.2013.00373

Taut, D., Pintea, S., Roovers, J.-P. W. R., Mananas, M.-A., \& Baban, A. (2017). Play seriously: Effectiveness of serious games and their features in motor rehabilitation. A meta-analysis. Neurorehabilitation, 41(1), 105-118. https://doi.org/10.3233/NRE-171462

Thimm, M., Fink, G. R., Küst, J., Karbe, H., \& Sturm, W. (2006). Impact of alertness training on spatial neglect: A behavioural and fMRI study. Neuropsychologia, 44(7), 1230-1246. https://doi.org/10.1016/j.neuropsychologia.2005.09.008

Tieri, G., Morone, G., Paolucci, S., \& losa, M. (2018). Virtual reality in cognitive and motor rehabilitation: Facts, fiction and fallacies. Expert Review of Medical Devices, 15(2), 107-117. Scopus. https://doi.org/10.1080/17434440.2018.1425613

Tobler-Ammann, B. C., Surer, E., Knols, R. H., Borghese, N. A., \& Bruin, E. D. de. (2017). User Perspectives on Exergames Designed to Explore the Hemineglected Space for Stroke Patients With Visuospatial Neglect: Usability Study. JMIR Serious Games, 5(3), e18. https://doi.org/10.2196/games.8013

Tsirlin, I., Dupierrix, E., Chokron, S., Coquillart, S., \& OhImann, T. (2009). Uses of Virtual Reality for Diagnosis, Rehabilitation and Study of Unilateral Spatial Neglect: Review and Analysis. CyberPsychology \& Behavior, 12(2), 175-181. https://doi.org/10.1089/cpb.2008.0208 
van der Kemp, J., Dorresteijn, M., Ten Brink, A. F., Nijboer, T. C. W., \& Visser-Meily, J. M. A. (2017). Pharmacological Treatment of Visuospatial Neglect: A Systematic Review. Journal of Stroke $\begin{array}{lll}\text { and } \quad \text { Cerebrovascular } & \text { 26(4), }\end{array}$ https://doi.org/10.1016/j.jstrokecerebrovasdis.2017.02.012

van Kessel, M. E., Geurts, A. C. H., Brouwer, W. H., \& Fasotti, L. (2013). Visual Scanning Training for Neglect after Stroke with and without a Computerized Lane Tracking Dual Task. Frontiers in Human Neuroscience, 7, 1-11. https://doi.org/10.3389/fnhum.2013.00358

van Nes, I. J. W., van der Linden, S., Hendricks, H. T., van Kuijk, A. A., Rulkens, M., Verhagen, W. I. M., \& Geurts, A. C. H. (2009). Is Visuospatial Hemineglect Really a Determinant of Postural Control Following Stroke? An Acute-Phase Study. Neurorehabilitation and Neural Repair, 23(6), 609614. https://doi.org/10.1177/1545968308328731

van Nes, I. J. W., van Kessel, M. E., Schils, F., Fasotti, L., Geurts, A. C. H., \& Kwakkel, G. (2009). Is Visuospatial Hemineglect Longitudinally Associated with Postural Imbalance in the Postacute Phase of Stroke? Neurorehabilitation and Neural Repair, 23(8), 819-824. https://doi.org/10.1177/1545968309336148

Van Vleet, T. M., \& DeGutis, J. M. (2013). The nonspatial side of spatial neglect and related approaches to treatment. Progress in Brain Research, 207, 327-349. https://doi.org/10.1016/B978-0-444$63327-9.00012-6$

Vanbecelaere, S., Berghe, K. V. den, Cornillie, F., Sasanguie, D., Reynvoet, B., \& Depaepe, F. (2020). The effectiveness of adaptive versus non-adaptive learning with digital educational games. Journal of Computer Assisted Learning, 36(4), 502-513. https://doi.org/10.1111/jcal.12416

Walker, R. (1996). Eye Patching and the Rehabilitation of Visual Neglect. Neuropsychological Rehabilitation, 6(3), 219-232. https://doi.org/10.1080/713755508 
Immersive VR Neglect Rehabilitation

Weintraub, S., \& Mesulam, M. M. (1988). Visual hemispatial inattention: Stimulus parameters and exploratory strategies. Journal of Neurology, Neurosurgery, and Psychiatry, 51(12), 14811488.

Wilkinson, P. (2016). A Brief History of Serious Games. In R. Dörner, S. Göbel, M. Kickmeier-Rust, M. Masuch, \& K. Zweig (Eds.), Entertainment Computing and Serious Games: International GIDagstuhl Seminar 15283, Dagstuhl Castle, Germany, July 5-10, 2015, Revised Selected Papers (pp. 17-41). Springer International Publishing. https://doi.org/10.1007/978-3-319-46152-6_2

Won-Seok, K., Nam-Jong, P., \& Sungmin, C. (2017). Development and validation of virtual prism adaptation therapy. 2017 International Conference on Virtual Rehabilitation (ICVR), 1-2. https://doi.org/10.1109/ICVR.2017.8007471

Yasuda, K., Muroi, D., Hirano, M., Saichi, K., \& Iwata, H. (2018). Differing effects of an immersive virtual reality programme on unilateral spatial neglect on activities of daily living. Case Reports, 2018. https://doi.org/10.1136/bcr-2017-222860

Yasuda, K., Muroi, D., Ohira, M., \& Iwata, H. (2017). Validation of an immersive virtual reality system for training near and far space neglect in individuals with stroke: A pilot study. Topics in Stroke Rehabilitation, 24(7), 533-538. https://doi.org/10.1080/10749357.2017.1351069 


\begin{tabular}{|c|c|c|c|c|c|c|c|c|c|c|}
\hline \multirow[b]{2}{*}{ Reference } & \multicolumn{4}{|c|}{ Sample } & \multicolumn{3}{|c|}{ Study design } & \multicolumn{2}{|c|}{ Outcome measures } & \multirow[b]{2}{*}{ Results } \\
\hline & $\mathbf{N}$ & TSS & Stroke & $\begin{array}{c}\text { Neglect } \\
\text { diagnosis }\end{array}$ & Main design & CG & Dose & Task & Index & \\
\hline \multirow{5}{*}{$\begin{array}{l}\text { (Katz et al., } \\
2005)\end{array}$} & \multirow{5}{*}{$\begin{array}{l}19, \\
\text { EG: } \\
11 \\
\text { CG: } \\
8\end{array}$} & \multirow{5}{*}{$\begin{array}{l}\text { EG: } \\
48 \\
\text { (SD }= \\
21) \\
\text { CG: } \\
36 \\
(S D= \\
10)\end{array}$} & \multirow{5}{*}{$\begin{array}{l}\text { RH first-ever } \\
\text { stroke }\end{array}$} & \multirow[t]{5}{*}{ NR } & \multirow{5}{*}{$\begin{array}{l}\text { Between-subject } \\
\text { design, random } \\
\text { group assignment }\end{array}$} & \multirow{5}{*}{$\begin{array}{l}8 \text { stroke patients } \\
\text { doing a computer } \\
\text { scanning training }\end{array}$} & \multirow{5}{*}{$\begin{array}{l}345 \text { minute } \\
\text { sessions / } \\
\text { week for } 4 \\
\text { weeks }\end{array}$} & BIT SCT & Contra- & \multirow{3}{*}{$\begin{array}{l}\text { No significant } \\
\text { interaction of } \\
\text { group } x \text { test } \\
\text { moment }\end{array}$} \\
\hline & & & & & & & & $\begin{array}{l}\text { Mesulam } \\
\text { Cancellation }\end{array}$ & lesional Hits & \\
\hline & & & & & & & & ADL checklist & Total score & \\
\hline & & & & & & & & $\begin{array}{l}\text { VR street } \\
\text { crossing test }\end{array}$ & $\begin{array}{l}\text { Times looked } \\
\text { at } L \text { and } R\end{array}$ & $\begin{array}{l}\text { EG improved } \\
\text { more than } C G\end{array}$ \\
\hline & & & & & & & & $\begin{array}{l}\text { Real street } \\
\text { crossing }\end{array}$ & $\begin{array}{l}\text { Accurate } \\
\text { decisions }\end{array}$ & NS \\
\hline \multirow[t]{2}{*}{$\begin{array}{l}\text { (Ansuini et } \\
\text { al., 2006) }\end{array}$} & \multirow[t]{2}{*}{6} & \multirow[t]{2}{*}{$\begin{array}{l}55-64 \\
d\end{array}$} & \multirow[t]{2}{*}{$\begin{array}{l}\text { RH stroke, } 3 \\
\text { fronto-parietal } \\
\text { (FP) and } 3 \\
\text { temporo-parietal } \\
\text { (TP) }\end{array}$} & \multirow[t]{2}{*}{$\begin{array}{l}\text { LB, Albert's line } \\
\text { cancellation, } \\
\text { SCT }\end{array}$} & \multirow[t]{2}{*}{ Pre-post } & \multirow[t]{2}{*}{3 healthy controls } & \multirow[t]{2}{*}{1 session } & $\begin{array}{l}\text { Sensory task in } \\
\text { virtual and real } \\
\text { conditions }\end{array}$ & $\begin{array}{l}\text { Indicating } \\
\text { position } \\
\text { target within } \\
4 \mathrm{~s}\end{array}$ & Only in FP group. \\
\hline & & & & & & & & Motor task & $\begin{array}{l}\text { Reach and } \\
\text { grasp target } \\
\text { within } 4 \mathrm{~s}\end{array}$ & Only in FP group. \\
\hline \multirow[t]{7}{*}{$\begin{array}{l}\text { (Kim et al., } \\
\text { 2007) }\end{array}$} & \multirow[t]{7}{*}{10} & \multirow[t]{7}{*}{ NR } & \multirow[t]{7}{*}{ RH stroke } & \multirow[t]{7}{*}{ NR } & \multirow{7}{*}{$\begin{array}{l}\text { Unbalanced } \\
\text { between-subject } \\
\text { design to validate } \\
\text { game }\end{array}$} & \multirow{7}{*}{$\begin{array}{l}\text { CG } 1=\text { little } \\
\text { computer } \\
\text { experience } \\
\text { CG } 2=\text { more } \\
\text { computer } \\
\text { experience }\end{array}$} & \multirow[t]{7}{*}{1 session } & $\begin{array}{l}\text { In-game } \\
\text { parameters }\end{array}$ & $\begin{array}{l}\text { Deviation } \\
\text { angle }\end{array}$ & \multirow{5}{*}{$\begin{array}{l}\text { Significant } \\
\text { difference with } \\
\text { CG 1, not with CG } \\
2\end{array}$} \\
\hline & & & & & & & & & RTs & \\
\hline & & & & & & & & & $\begin{array}{l}\text { Need visual } \\
\text { cue }\end{array}$ & \\
\hline & & & & & & & & & $\begin{array}{l}\text { Need auditory } \\
\text { cue }\end{array}$ & \\
\hline & & & & & & & & & Failed trials & \\
\hline & & & & & & & & Albert test & $L-R$ & Unclear \\
\hline & & & & & & & & Diller test & L-R & NS \\
\hline
\end{tabular}

Note. TSS $=$ time since stroke, Total Hits $=$ percentage or total number of detected targets. SCT $=$ star cancellation test, $\mathrm{BTT}=$ baking tray task, $\mathrm{LB}=$ line bisection, $\mathrm{DBE}=$ directional bisection error, $\mathrm{CBS}=$ Catherina Bergego Scale. Chronic stroke $=>6$ months, Sub-acute $=1-6$ months, Acute $<1$ month. CG $=$ control group. NR $=$ not reported. NA $=$ not applicable. $\mathrm{MI}=$ Mean improvement. 
Table S1 (continued). Design of previous VR neglect rehabilitation studies.

\begin{tabular}{|c|c|c|c|c|c|c|c|c|c|c|}
\hline \multirow{2}{*}{ Reference } & \multicolumn{4}{|c|}{ Sample } & \multicolumn{3}{|c|}{ Study design } & \multicolumn{2}{|c|}{ Outcome measures } & \multirow{2}{*}{$\begin{array}{c}\text { Results } \\
\text { Significant? }\end{array}$} \\
\hline & $\mathbf{N}$ & TSS & Stroke & Neglect diagnosis & Main design & CG & Dose & Task & Index & \\
\hline $\begin{array}{l}\text { (Mainetti et al., } \\
\text { 2013) }\end{array}$ & 1 & $1 y$ & $\begin{array}{l}\text { RH fronto- } \\
\text { temporal } \\
\text { hemorrhagic } \\
\text { lesion }\end{array}$ & Albert, Diller, LB & $\begin{array}{l}\text { Pre-post design with } 5 \\
\text { month follow-up }\end{array}$ & No & $\begin{array}{l}30 \text { min / day, } 5 \\
\text { days / week for } \\
1 \text { month }\end{array}$ & LB & DBE & $S$ \\
\hline \multirow{4}{*}{$\begin{array}{l}\text { (Sedda et al., } \\
\text { 2013) }\end{array}$} & \multirow[t]{4}{*}{1} & \multirow{4}{*}{ Chronic } & \multirow{4}{*}{$\begin{array}{l}\text { RH hemorrhagic } \\
\text { stroke }\end{array}$} & \multirow{4}{*}{$\begin{array}{l}\text { Neuro-psychological } \\
\text { assessment } \\
\text { (unspecified) }\end{array}$} & \multirow{4}{*}{$\begin{array}{l}\text { Pre-post: } 1 \text { baseline } \\
\text { assessment, } 1 \text { post- } \\
\text { assessment, } 1 \text { follow- } \\
\text { up at } 5 \text { months }\end{array}$} & \multirow[t]{4}{*}{ No } & \multirow{4}{*}{$\begin{array}{l}1 \text { hour / day } \\
\text { for four weeks }\end{array}$} & Albert test & & \multirow{4}{*}{$\begin{array}{l}\text { Unclear } \\
\text { NS }\end{array}$} \\
\hline & & & & & & & & Diller test & & \\
\hline & & & & & & & & Line bisection & L-R & \\
\hline & & & & & & & & $\begin{array}{l}\text { Albert } \\
\text { cancellation } \\
\text { test }\end{array}$ & & \\
\hline \multirow[t]{7}{*}{$\begin{array}{l}\text { (van Kessel et } \\
\text { al., 2013) }\end{array}$} & \multirow[t]{7}{*}{29} & \multirow[t]{7}{*}{$\begin{array}{l}57-569 \\
\text { days }\end{array}$} & \multirow[t]{7}{*}{ RH stroke } & \multirow{7}{*}{$\begin{array}{l}\text { Total omissions }>\text { cut-off } \\
\text { on at least three neglect } \\
\text { tests }+ \text { at least one } \\
\text { observational scale }\end{array}$} & \multirow{7}{*}{ 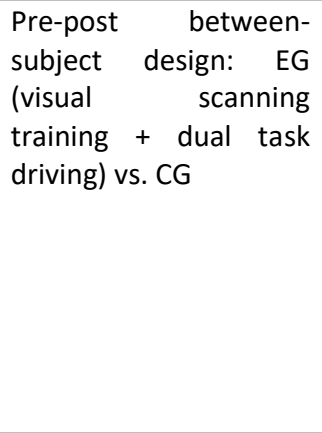 } & \multirow{7}{*}{$\begin{array}{lr}15 \text { stroke } \\
\text { patients lane } \\
\text { tracking in } \\
\text { drive simulator }\end{array}$} & \multirow{7}{*}{$\begin{array}{l}\text { Lane tracking: } \\
15 \text { minutes for } \\
6 \text { days across } 6 \\
\text { weeks } \\
\text { Dual task: } \\
35 \text { minutes for } \\
2 \text { days across } 3 \\
\text { weeks }\end{array}$} & BIT LIC & $\begin{array}{l}\text { Total } \\
\text { omissions }\end{array}$ & \multirow[t]{7}{*}{ NS } \\
\hline & & & & & & & & BIT LEC & L-R & \\
\hline & & & & & & & & Bells test & $\begin{array}{l}\text { Total } \\
\text { omissions }\end{array}$ & \\
\hline & & & & & & & & LB & $\begin{array}{l}\text { Total } \\
\text { omissions }\end{array}$ & \\
\hline & & & & & & & & Word reading & $\begin{array}{l}\mathrm{L}-\mathrm{R} \text { errors / } \\
\text { total errors }\end{array}$ & \\
\hline & & & & & & & & Grey scales & L-R bias & \\
\hline & & & & & & & & BTT & L-R & \\
\hline \multirow{2}{*}{$\begin{array}{l}\text { (Aravind \& } \\
\text { Lamontagne, } \\
\text { 2014) }\end{array}$} & \multirow[t]{2}{*}{12} & \multirow[t]{2}{*}{$\begin{array}{l}3-90 \\
\text { months }\end{array}$} & \multirow[t]{2}{*}{$\mathrm{RH}$ and $\mathrm{LH}$} & \multirow{2}{*}{$\begin{array}{l}\text { Clinical diagnosis based } \\
\text { on motor fee visual } \\
\text { perceptual test and Star } \\
\text { cancellation }\end{array}$} & \multirow{2}{*}{$\begin{array}{l}\text { Within-subject design } \\
\text { comparing obstacle } \\
\text { avoidance between } \\
\text { contra- and ipsilesional } \\
\text { side }\end{array}$} & \multirow[t]{2}{*}{ No } & \multirow[t]{2}{*}{1 session } & \multirow[t]{2}{*}{$\begin{array}{l}\text { In-game } \\
\text { parameters }\end{array}$} & $\begin{array}{l}\text { Detection } \\
\text { time }\end{array}$ & \multirow[t]{2}{*}{$S$} \\
\hline & & & & & & & & & $\begin{array}{l}\text { Number of } \\
\text { colissions }\end{array}$ & \\
\hline
\end{tabular}

Note. TSS = time since stroke, Total Hits $=$ percentage or total number of detected targets. SCT $=$ star cancellation test, $\mathrm{BTT}=$ baking tray task, LB $=$ line bisection, $\mathrm{DBE}=$ directional bisection error, $\mathrm{CBS}=$ Catherina Bergego Scale. Chronic stroke $=>6$ months, Sub-acute $=1-6$ months, Acute $<1$ month. CG $=$ control group. NR $=$ not reported. NA $=$ not applicable. $\mathrm{MI}=$ Mean improvement. 
Table S1 (continued). Design of previous VR neglect rehabilitation studies.

\begin{tabular}{|c|c|c|c|c|c|c|c|c|c|c|}
\hline \multirow[b]{2}{*}{ Reference } & \multicolumn{4}{|c|}{ Sample } & \multicolumn{3}{|c|}{ Study design } & \multicolumn{2}{|c|}{ Outcome measures } & \multirow[b]{2}{*}{ Results } \\
\hline & $\mathbf{N}$ & TSS & Stroke & $\begin{array}{l}\text { Neglect } \\
\text { diagnosis }\end{array}$ & Main design & CG & Dose & Task & Index & \\
\hline \multirow{5}{*}{$\begin{array}{l}\text { (Fordell et al., } \\
\text { 2016) }\end{array}$} & \multirow[t]{5}{*}{15} & \multirow[t]{5}{*}{ Chronic } & \multirow[t]{5}{*}{$\mathrm{RH}$ ischemic infarct } & \multirow{5}{*}{$\begin{array}{l}1 / 4 \text { neglect } \\
\text { tests below } \\
\text { cut-off }+ \text { CBS }\end{array}$} & \multirow{5}{*}{$\begin{array}{l}\text { Multiple baseline: } 3 \\
\text { baseline assessments, } \\
\text { follow-up within a weak } \\
\text { and after } 25 \text { weeks }\end{array}$} & \multirow[t]{5}{*}{ No } & \multirow{5}{*}{$\begin{array}{l}15 \text { hours } \\
\text { spread across } \\
5 \text { weeks }\end{array}$} & $\mathrm{SCT}$ & Total hits & \multirow[t]{2}{*}{ Significant } \\
\hline & & & & & & & & BTT & $\begin{array}{l}\text { Ipsilesional } \\
\text { hits }\end{array}$ & \\
\hline & & & & & & & & LB & DBE & NS \\
\hline & & & & & & & & Extinction & Total misses & Significant \\
\hline & & & & & & & & Posner & RT total & NS \\
\hline \multirow{3}{*}{$\begin{array}{l}\text { (Pirovano et al., } \\
\text { 2016; Tobler- } \\
\text { Ammann et al., } \\
\text { 2017) }\end{array}$} & \multirow[t]{3}{*}{7} & \multirow[t]{3}{*}{$\begin{array}{l}M=46 \\
\text { days, } S D= \\
31 \text { days }\end{array}$} & \multirow[t]{3}{*}{$\begin{array}{l}\text { RH ischemic and } \\
\text { hemorrhagic first- } \\
\text { ever stroke }\end{array}$} & \multirow[t]{3}{*}{ CBS } & \multirow[t]{3}{*}{$\begin{array}{l}\text { Usability evaluation of } \\
\text { patients and therapists }\end{array}$} & \multirow[t]{3}{*}{ No } & \multirow{3}{*}{$\begin{array}{l}15 \text { sessions of } \\
30 \text { minutes } \\
\text { across } 3 \\
\text { weeks }\end{array}$} & \multirow{3}{*}{$\begin{array}{l}\text { Usability } \\
\text { Questionnaire on 7- } \\
\text { point scale (4 = } \\
\text { neutral) }\end{array}$} & $\begin{array}{l}\text { Perceived } \\
\text { user- } \\
\text { friendliness }\end{array}$ & $\begin{array}{l}M=5.6, S D= \\
1.4\end{array}$ \\
\hline & & & & & & & & & Attitudes & $\begin{array}{l}\mathrm{M}=4.8, \mathrm{SD}= \\
1.9\end{array}$ \\
\hline & & & & & & & & & $\begin{array}{l}\text { Intention to } \\
\text { use }\end{array}$ & $\begin{array}{l}\mathrm{M}=3.9, \mathrm{SD}= \\
2.1\end{array}$ \\
\hline \multirow[t]{4}{*}{$\begin{array}{l}\text { (Yasuda et al., } \\
\text { 2017) }\end{array}$} & \multirow[t]{4}{*}{10} & \multirow[t]{4}{*}{$\begin{array}{l}30-129 \\
\text { days }\end{array}$} & \multirow[t]{4}{*}{$\begin{array}{l}\mathrm{RH} \text { ischemic and } \\
\text { hemorrhagic stroke }\end{array}$} & \multirow[t]{4}{*}{$\begin{array}{l}\text { BIT standard } \\
\text { cut-off values }\end{array}$} & \multirow[t]{4}{*}{ Pre-post } & \multirow[t]{4}{*}{ No } & \multirow[t]{4}{*}{1 session } & LIC & Total hits & $\begin{array}{l}\text { Near space: NS } \\
\text { Far space: } \mathrm{S}\end{array}$ \\
\hline & & & & & & & & SCT & Total hits & $\begin{array}{l}\text { Near space: NS } \\
\text { Far space: } \mathrm{S}\end{array}$ \\
\hline & & & & & & & & BIT LB & DBE & $\begin{array}{l}\text { Near space: NS } \\
\text { Far space: NS }\end{array}$ \\
\hline & & & & & & & & LEC & Total hits & $\begin{array}{l}\text { Near space: NS } \\
\text { Far space: } \mathrm{S}\end{array}$ \\
\hline \multirow{3}{*}{$\begin{array}{l}\text { (Yasuda et al., } \\
\text { 2018) }\end{array}$} & \multirow[t]{3}{*}{1} & \multirow[t]{3}{*}{72 days } & $\mathrm{RH}$ lesion in the & NIHSS, LIC, & Pre-post ( 2 baseline & No & 30 sessions of & LIC & Omission rate & Not statistically \\
\hline & & & frontal, temporal & behavioral & assessments) & & 30 minutes & BIT LB & DBE & tested \\
\hline & & & and parietal lobes & observation & & & over 6 weeks & CBS & Total score & $\begin{array}{l}\text { No } \\
\text { improvement }\end{array}$ \\
\hline $\begin{array}{l}\text { (Luca et al., } \\
\text { 2019) }\end{array}$ & 1 & NR & $\begin{array}{l}\text { RH subarachnoid } \\
\text { hemorrhage }\end{array}$ & NR & Pre-post $A B$ design & No & $\begin{array}{l}20 \text { sessions } \\
\text { with shadow, } \\
20 \text { without }\end{array}$ & BIT & Total hits & $\begin{array}{l}\text { Significant in } \\
4 / 16 \text { subtests at } \\
.05\end{array}$ \\
\hline & & & & & & & shadow & MMSE & Total score & NS \\
\hline & & & & & & & & EEG & P300 & Significant \\
\hline
\end{tabular}

Note. TSS = time since stroke, Total Hits = percentage or total number of detected targets. LEC = BIT letter cancellation, LIC $=$ BIT line cancellation, SCT $=$ BIT star cancellation, BTT = baking tray task, $\mathrm{LB}=$ line bisection, $\mathrm{DBE}=$ directional bisection error, $\mathrm{CBS}=$ Catherina Bergego Scale. Chronic stroke $=>6$ months, Sub-acute $=1-6$ months, Acute $<1$ month. $\mathrm{CG}=$ control group.

$\mathrm{NR}=$ not reported. $\mathrm{NA}=$ not applicable. $\mathrm{MI}=$ Mean improvement. NIHSS = National Institutes of Health Stroke Scale 
Table S2. Overview of the main adjustments made throughout the game development process.

\begin{tabular}{|c|c|c|c|c|c|c|c|c|}
\hline \multirow{2}{*}{$\begin{array}{l}\text { Game } \\
\text { version }\end{array}$} & \multicolumn{2}{|c|}{ Target locations } & \multicolumn{3}{|c|}{ Scores and feedback } & \multicolumn{3}{|c|}{ User interface } \\
\hline & $\begin{array}{l}\text { Patient- } \\
\text { tailored }\end{array}$ & Head orientation & Level progression & Score adjustment & $\begin{array}{l}\text { Probability of } \\
\text { reward }\end{array}$ & Text & Touch controllers & Pause \\
\hline v1.3 & $\begin{array}{l}\mathrm{CoC} \\
\text { algorithm }\end{array}$ & $\begin{array}{l}\text { Not adjusted } \\
\text { according to head } \\
\text { orientation }\end{array}$ & $\begin{array}{c}\text { Finish level after a } \\
\text { certain number of } \\
\text { hits }\end{array}$ & Fixed score per hit & $100 \%$ & $\begin{array}{l}\text { No text } \\
\text { cueing }\end{array}$ & $\begin{array}{l}\text { Button A for target discrimination } \\
\text { and for confirming selections. }\end{array}$ & $\begin{array}{l}\text { Press two triggers at } \\
\text { same time. }\end{array}$ \\
\hline v1.5 & $\begin{array}{c}\mathrm{CoC} \\
\text { algorithm }\end{array}$ & $\begin{array}{l}\text { Not adjusted } \\
\text { according to head } \\
\text { orientation }\end{array}$ & $\begin{array}{c}\text { Finish level after a } \\
\text { certain number of } \\
\text { hits }\end{array}$ & Fixed score per hit & $100 \%$ & $\begin{array}{l}\text { No text } \\
\text { cueing }\end{array}$ & $\begin{array}{l}\text { Button A for target discrimination } \\
\text { and for confirming selections. }\end{array}$ & $\begin{array}{l}\text { Press two triggers at } \\
\text { same time. }\end{array}$ \\
\hline v1.6 & $\begin{array}{c}\mathrm{CoC} \\
\text { algorithm }\end{array}$ & $\begin{array}{l}\text { Not adjusted } \\
\text { according to head } \\
\text { orientation }\end{array}$ & $\begin{array}{c}\text { Finish level after a } \\
\text { certain number of } \\
\text { hits }\end{array}$ & Fixed score per hit & $100 \%$ & $\begin{array}{l}\text { No text } \\
\text { cueing }\end{array}$ & $\begin{array}{l}\text { Button A only for target } \\
\text { discrimination. Confirmation of } \\
\text { selection with index trigger. }\end{array}$ & $\begin{array}{l}\text { Press and release } \\
\text { joystick. }\end{array}$ \\
\hline v1.7 & $\begin{array}{l}\mathrm{CoC} \\
\text { algorithm }\end{array}$ & $\begin{array}{l}\text { Adjusted according } \\
\text { to head orientation }\end{array}$ & $\begin{array}{l}\text { Finish level after a } \\
\text { certain number of } \\
\text { hits }\end{array}$ & Fixed score per hit & $25 \%$ & $\begin{array}{l}\text { No text } \\
\text { cueing }\end{array}$ & $\begin{array}{l}\text { Button A only for target } \\
\text { discrimination. Confirmation of } \\
\text { selection with index trigger. }\end{array}$ & $\begin{array}{l}\text { Press and release } \\
\text { joystick. }\end{array}$ \\
\hline $\mathrm{v} 1.8$ & $\begin{array}{l}\text { Logistic } \\
\text { algorithm }\end{array}$ & $\begin{array}{l}\text { Adjusted according } \\
\text { to head orientation }\end{array}$ & $\begin{array}{l}\text { Finish level after } \\
\text { certain score }\end{array}$ & $\begin{array}{l}\text { Score adjusted on } \\
\text { performance }\end{array}$ & $25 \%$ & $\begin{array}{l}\text { Text } \\
\text { cueing }\end{array}$ & $\begin{array}{l}\text { Button A only for target } \\
\text { discrimination. Confirmation of } \\
\text { selection with index trigger. }\end{array}$ & $\begin{array}{c}\text { Press and release } \\
\text { joystick. + Headset } \\
\text { removed. }\end{array}$ \\
\hline v1.9.2.1 & $\begin{array}{l}\text { Logistic } \\
\text { algorithm }\end{array}$ & $\begin{array}{l}\text { Adjusted according } \\
\text { to head orientation }\end{array}$ & $\begin{array}{l}\text { Finish level after } \\
\text { certain score }\end{array}$ & $\begin{array}{l}\text { Score adjusted on } \\
\text { performance }\end{array}$ & $25 \%$ & $\begin{array}{l}\text { Text } \\
\text { cueing }\end{array}$ & $\begin{array}{l}\text { Button A only for target } \\
\text { discrimination. Confirmation of } \\
\text { selection with index trigger. }\end{array}$ & $\begin{array}{c}\text { Press and release } \\
\text { joystick. + Headset } \\
\text { removed. }\end{array}$ \\
\hline
\end{tabular}

